\title{
Searching for Nucleic Acid Alternatives
}

\author{
Albert Eschenmoser
}

\begin{abstract}
Back of the envelope" methods have their place in experimental chemical research; they are effective mediators in the generation of research ideas, for instance, the design of molecular structures. Their qualitative character is part of their strength, rather than a drawback for the role they have to play. Qualitative conformational analysis of oligonucleotide and other oligomer systems on the level of idealized conformations is one such method; it has played a helpful role in our work on the chemical etiology of nucleic acid structure. This article, while giving a short overview of that work, shows how.
\end{abstract}

Keywords: Conformational analysis of oligonucleotides · Nucleic acid analogs · Oligonucleodipeptides · p-RNA . TNA $\cdot$ Watson-Crick base-pairing

Chemists understand by comparing, not ' $a b$ initio'. To perceive and to create opportunities for drawing conclusions on the basis of comparisons is the organic chemist's way of interpreting and exploring the world at the molecular level. Comparing the properties of molecules of unknown constitution with those of already known constitution was the basic strategy in classical chemistry of structure determination by chemical methods, and still the same largely holds for more recent structure determinations in chemical laboratories by physical methods; it is only with regard to X-ray structure analysis that the statement ceases to hold in as far as chemistry is concerned. Model studies, an approach characteristically chosen by chemists when confronted with

\footnotetext{
${ }^{*}$ Correspondence: Prof. Dr. A. Eschenmoser Laboratory of Organic Chemistry

ETH Hönggerberg, $\mathrm{HCl}-\mathrm{H} 309$

$\mathrm{CH}-8093$ Zürich

Tel.: +4144632 2893

E-Mail: eschenmoser@org.chem.ethz.ch

and: The Scripps Research Institute (TSRI)

10550 North Torrey Pines Road

La Jolla, California 92037, USA
}

structural or transformational complexity, serve the purpose of creating opportunities to compare the behavior of complex systems with that of simpler ones. Enzymic reactions and enzyme models are examples.

To reach understanding of structures and structural transformations through comparing is not what only chemists are aiming at, it is true also for biologists, both dealing with their own spatial and temporal as well as conceptual resolution of their objects. Yet, biology is also a historic science: ever since the time of Charles Darwin, biologists - besides and beyond studying structure and function - ponder the origin of their objects. Chemists do not have to; pursuing the question of origin with regard to the constituents of the periodic table is the job of cosmologists. However, with the progressing breakdown of borders between biology and (a very large part of) contemporary chemistry, the search for origins is bound to leap over from biology to chemistry, the quest for comprehending the evolution of living organisms will have its extension in the quest for an understanding of the origin of biomolecular structures. I do not mean the understanding of the origin of biomolecules in terms of their biosynthesis, but rather the origin of these biosyntheses themselves and, in the long term, of biogenesis, at the molecular level.

To systematically compare selected chemical properties of structural nucleic acid analogs with corresponding properties of the natural system is part of a project pursued in my research group(s) since 1986; the aim is to explore the potential of organic chemistry to arrive at an understanding of how and why Nature came to choose the specific structure type of the nucleic acids we know today as the molecular basis of genetic function. The specific property to be compared in this work is a given nucleic acid alternative's capacity for informational Watson-Crick nucleobase-pairing, the overall criterion for the selection for study of a given system being a structure's potential for constitutional self-assembly as compared to that envisaged for the structure of the natural system itself [1].

There is another motive for pursuing in organic and medicinal chemistry laboratories the search for nucleic acid analogs: the worldwide run, also since the late 1980s, after nucleic acid substitutes that might be useful in medicinal anti-sense technology [2]. This kind of search is not subjected to the above-mentioned selection criterion that rather strictly narrows the choice of oligomer systems for study by demanding them to be potentially natural systems. Nevertheless, antisense-technology driven search for nucleic acid substitutes is not only very successful (chemically) in pursuing its own goals, some of its results importantly also complement etiology-oriented research on nucleic acid alternatives by corroborating and extending one of the major conclusions to be drawn from the latter, namely that, in contrast to what was believed before, the capability of informational Watson-Crick base-pairing is by no means limited to the structure type of the Watson-Crick double helix. Quite on the contrary, it is widespread among oligomers containing backbones that may be quite different from the one of the natural nucleic acids. Nielsen's PNA exemplifies perhaps most instructively the degree of structural backbone variation Watson-Crick base-pairing is found to be compatible with. 
This wide spread of biology's genetic type of recognition process notwithstanding, an oligomer system's capability to show informational base-pairing demands rather stringent prerequisites to be fulfilled regarding the backbone structure and the three-dimensional relationship between backbone units and recognition elements (nucleobases). There is not just the question "base-pairing, yes or no?"; informational oligomer systems may "speak different base-pairing languages" in the sense that they can be capable of undergoing intra-system base-pairing with themselves, while being unable to communicate with each other by inter-system cross-pairing. To deduce from empirical as well as theoretical sources the structural constraints that control an oligomer system's capability of base-pairing in a given language would be important for eventually being able on a qualitative level to estimate in advance, if not to predict, whether or not a given type of oligomer structure could act as an informational oligomer. This challenge is clearly addressed to researchers in both branches of nucleic acid chemistry mentioned above, etiology-oriented as well as anti-sense technology driven.

From its very beginning, our own work was assisted by a set of such empirical qualitative criteria, a set that evolved with time and experience. In retrospect, it seems quite instructive to look at the balance between success and failure experienced so far in applying these criteria for "predicting' base-pairing capability for new oligomer systems. I review them in this article by pointing to their origin, summarizing their essentials, commenting on their strengths and weaknesses as well as their potential to be extended and applied for oligomer systems structurally different from those for which these rules were deduced and developed. I am, of course, not unaware of the fact that in contemporary chemistry the task of predicting for practical purposes the structure (and sometimes implicitly the properties) of molecules is to be pursued by theory-based and computer-assisted tools; yet this does not mean that efforts to reach such estimates by empirical arguments on a qualitative level have become obsolete; after all, the experimental chemist's pragmatic reasoning in terms of his classical formulae language coexists quite successfully with the kind of reasoning feasible on the level of quantum chemistry.

Our entry into the research field of nucleic acid chemistry was motivated by our interest in the broader context of an organic chemistry of biogenesis [3], and consisted in an experimental study on the formation and properties of oligo-dipeptamidinium salts (1982-1986, with Heinz Moser and Arthur Steiger [4]). At the outset of this project stood the recognition of the fact that

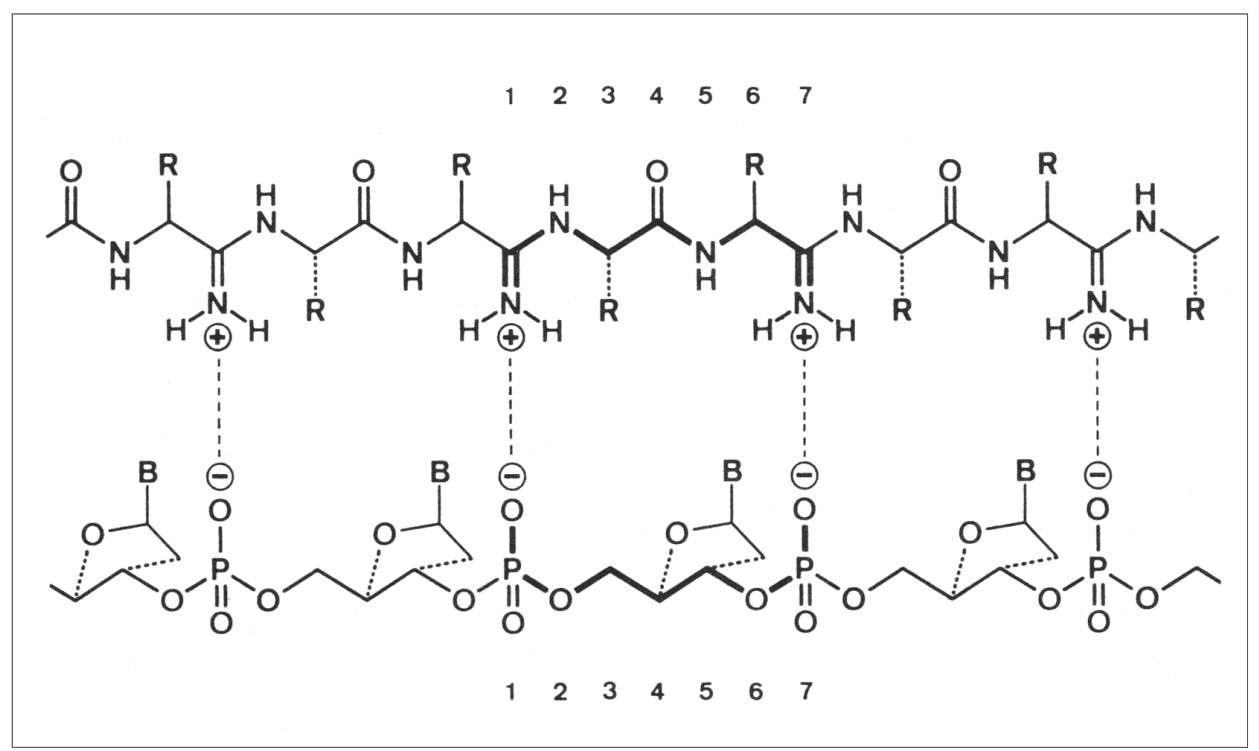

Fig. 1. Six-bonds periodicity in oligonucleotides and oligo-dipeptamidinium salts (facsimile from [4])

the constitutional periodicity of a negatively charged oligonucleotide chain happens to be identical (six covalent bonds) with that of the chain of a positively charged oligodipeptamidinium salt, that is, of a polypeptide chain in which each second backbone amide group is replaced by a cationic amidinium group (Fig. 1). The driving force behind the project was the question as to whether such an (etiologically not necessarily accidental) identity of constitutional periodicity in the two major types of biopolymer could give rise to a mutual catalysis in the formation of oligonucleotide and oligo-dipeptamidinium strands by oligomerization of their respective monomers, given that oligo-dipeptamidinium salts can be considered to be oligomerization products of (the ammonium form of) dipeptide nitriles and could transform to corresponding oligopeptides under mild hydrolytic conditions. Experiments turned out to negate neither the feasibility of the oligomerization step (preferably catalyzed by thiols such as cysteine [5]), nor the hydrolytic conversion to oligopeptides, yet uncovered strand fission to be a competing process in that hydrolysis and, moreover, the overall stability of oligo-dipeptamidium salts toward such cleavage near neutral $\mathrm{pH}$ to be quite low [6].

One special aspect of that early project, namely the remarkable constitutional relationship between an oligo-nucleotide and oligo-dipeptide chain, was to induce our next move. Only little was needed to realize that the complementarity of charges may be extended to the complementarity of other recognition elements, most appealingly of course, nucleobases. Such a step called for nucleic acid alternatives composed of homochiral oligo-dipeptamidinium and also oligo-dipeptide chains in which each second alpha-amino acid would be tagged by a nucleobase (Fig. 2a,b). We studied (with Peter Lohse [6]) the formation and the properties of such nucleobase-tagged oligo-dipeptamidinium salts with partial success, yet eventually succumbed to their relative instability. The literature existing at the time (1986) already contained reports on pioneering experimental efforts to prepare oligopeptides composed of nucleobase-tagged alpha-amino acids, however, these reports were devoid of considerations according to which tagged oligomer units should be a dipeptide unit [7]. Encouraged by an ETH-built (only slightly 'suffering') mechanical model of a double-helical hybrid duplex between an oligonucleotide chain and a nucleobase-tagged oligo-dipeptide chain, Gerhard Baschang of (former) CIBA-Geigy's newly formed 'anti-sense group' synthesized in 1986 an octamer of an L-alanyl-glycyl type oligomer in which each L-alanine was replaced by a L-serine derived L-(1-thyminyl)-alanine (Fig 2b). Disappointingly, no base-pairing with polyd-adenosine was observed of that (presumably earliest) sample of a constitutionally and stereochemically defined nucleobasetagged oligo-dipeptide [8]. In the light of this experience, Peter Nielsen's pragmatically and ingeniously designed and, in turn, dramatically successful 'peptide nucleic acid' a few years later amounted to an overwhelming discovery [9]. Reassuringly, the periodicity of the nucleobase-tagging of PNA's backbone nicely corresponded to that of an oligo-dipeptide type of oligomer structure (Fig. 2c).

Gradually overlapping with our early steps toward oligo-dipeptide based informational systems in the 1980s was our search for nucleic acid alternatives that contain phosphodiester backbones derived from hexopyranoses in place of ribofuranose units ("Why pentose and not hexose nucleic acids?" [10] Fig. 3). While our results of an 
a<smiles>CCNC(=O)[C@H](Cn1cc(C)c(=O)[nH]c1=O)NC(=[NH2+])CNC</smiles><smiles>CCNC(=O)[C@H](Cn1cc(C)c(=O)[nH]c1=O)NC=N</smiles><smiles>CC(=O)[C@H](Cn1cc(C)c(=O)[nH]c1=O)NC=N</smiles>

b<smiles>CNCC(=O)N[C@@H](Cn1cc(C)c(=O)[nH]c1=O)C(=O)NCC(=O)N[C@@H](Cn1cc(C)c(=O)[nH]c1=O)C(=O)NCC(=O)N[C@@H](Cn1cc(C)c(=O)[nH]c1=O)C(C)=O</smiles>

C<smiles>CNCCN(CC(=O)NCCN(CC(=O)NCCN(CC(C)=O)C(=O)Cn1cc(C)c(=O)[nH]c1=O)C(=O)Cn1cc(C)c(=O)[nH]c1=O)C(=O)Cn1cc(C)c(=O)[nH]c1=O</smiles>

Fig. 2. Six-bond periodicity in oligo-nucleodipeptamidinium salts (a), oligo-nucleodipeptides (b) and Nielsen's PNA (c)

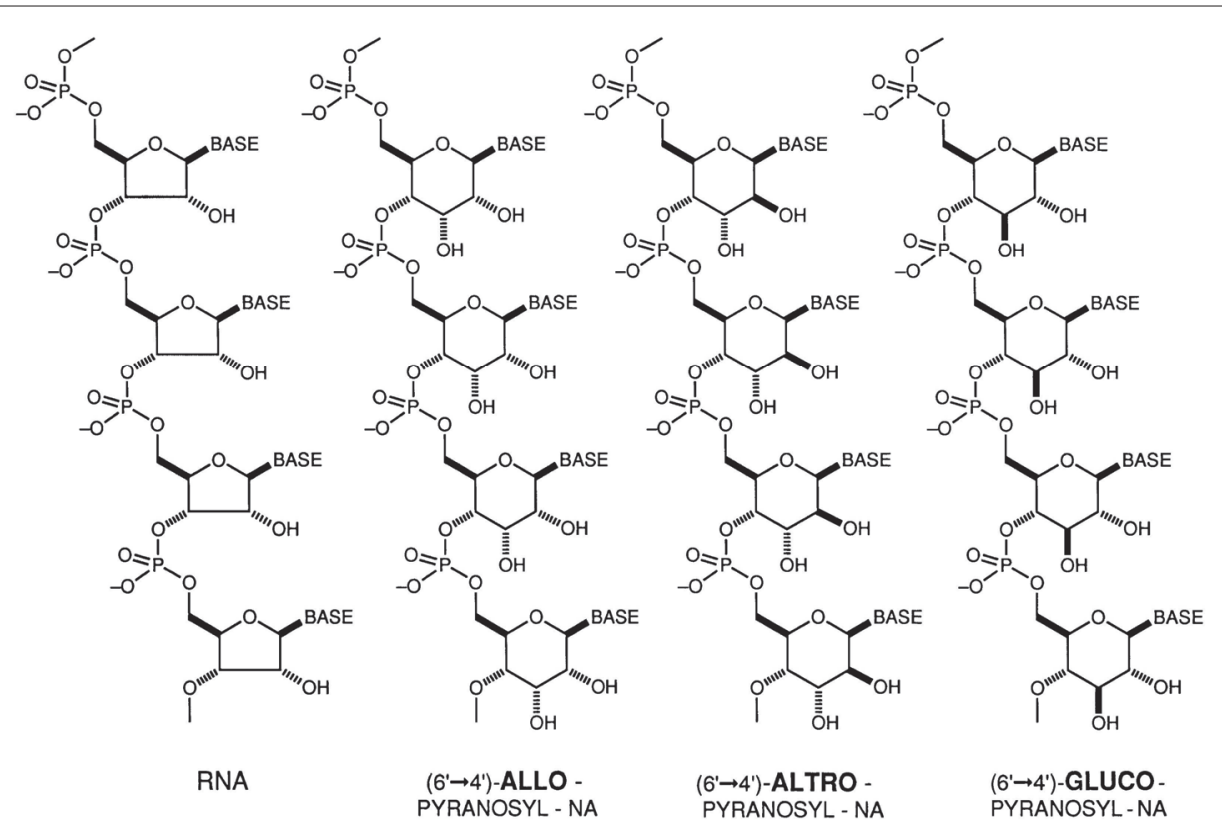

Fig. 3. Three (potentially natural) hexopyranosyl alternatives of RNA studied in our laboratory [11-13]. The model system homo-DNA lacks the hydroxyl groups in positions $2^{\prime}$ and $3^{\prime}$. extensive study of the (diastereoselective) aldolization of glycolaldehyde phosphate [14] had initiated these studies, it was mainly the following aspect that eventually led us to rigorously concentrate on this project: an assignment of etiological relevance to a given nucleic acid alternative will be the more reliable, the closer the structural and generational relationships between the alternative and the natural system is. The structure of an alternative should be derivable from an alternative aldose by the same type of chemistry that allows us to derive the structure of RNA from ribose. What in addition made such a study appealing from a purely chemical point of view was the following: oligonucleotide strands composed of hexopyranose sugar units would be amenable to qualitative conformational rationalization, in sharp contrast to the conformationally far more complex pentofuranose-based natural systems, the base-pairing capability of which had, at the time, never been rationalized at the level of the organic chemist's qualitative way of conformational reasoning.

Fig. 4 reproduces the results of the kind of conformational analysis that allowed us to 'predict' that pyranose analogs of DNA ('homo-DNA') might have the capability of informational base-pairing. The analysis was based on the following framework of assumptions and stipulations [10][15]:

1. Search for the ensemble of (formally) least strained conformers of an oligomer chain's constitutionally repeating monomer unit by restricting the rotational continuum around each covalent bond of the backbone to three ideally staggered (= 'idealized') conformations (bidentate oxygen centers containing two electron lone-pairs taken as tetrahedral centers);

2. Least strained conformers of a monomer unit are those that have either no, or the smallest possible number of, '1,5-repulsions' (= repulsions resulting whenever in a 5-center chain $a-b-c-d-e$ the two bonds $a-b$ and $d-e$ are positioned parallel to each other and, at the same time, neither $a$ nor $e$ is a hydrogen atom);

3. Phosphodiester group conformations are allowed to be gauche-gauche or gauche-trans, but not trans-trans [16];

4. An oligomer system can be expected to be a base-pairing system if the ensemble of (formally) least strained monomerunit conformers contains at least one conformer that is in a "pairing conformation';

5. A 'pairing conformation' of a monomer unit conformer is a conformation that repeats itself in both neighboring monomer units.

It is to be noted that in such an analysis, based on idealized conformations, the criteria 'conformational repetitivity of a 


\section{Phosphodiester conformations -sc/-sc and +sc/+sc}
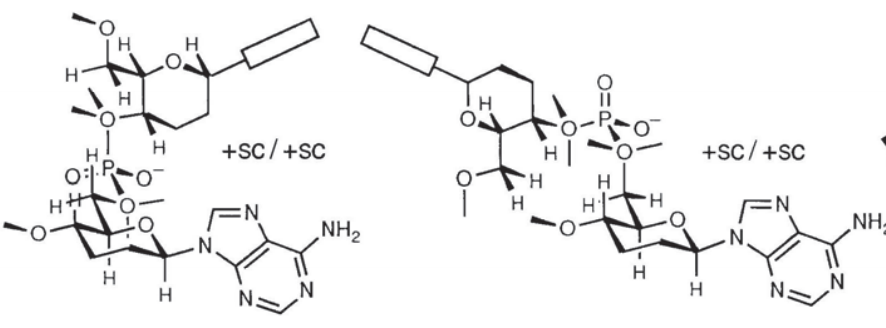

non - repetitive

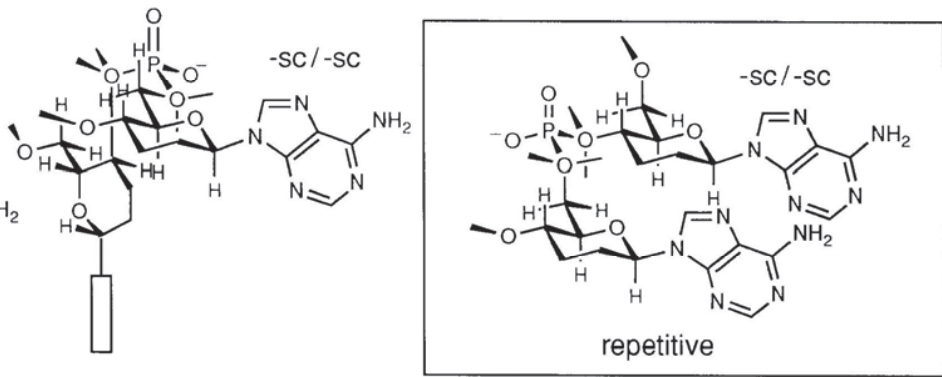

Phosphodiester conformations ap $/ \pm \mathrm{sc}$ and $\pm \mathrm{sc} /$ ap
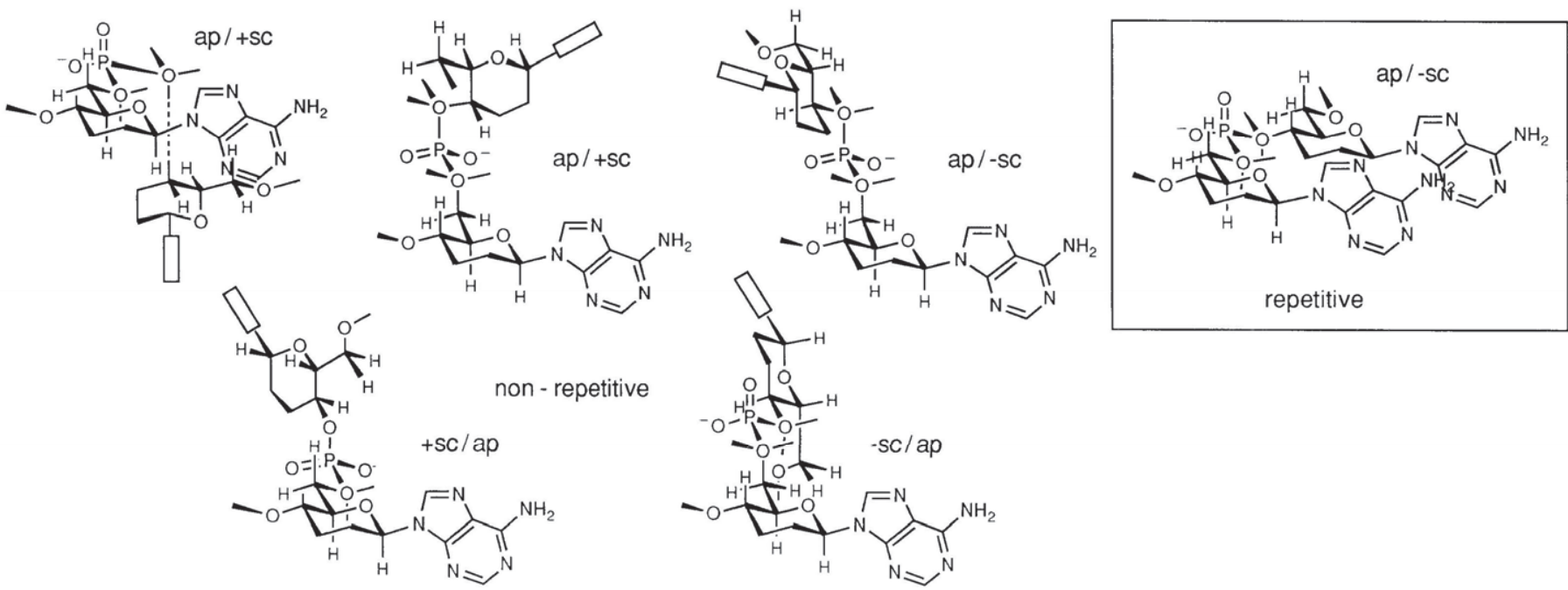

Fig. 4. Result of the qualitative conformational analysis of the homo-DNA backbone using idealized conformations [10][15]. The Fig. depicts the ensemble of least strained monomer unit conformers of which the two pairing conformations are framed $(-\mathrm{sc} / \mathrm{sc}=-\mathrm{g} /-\mathrm{g}$ and $\mathrm{ap} /-\mathrm{sc}=-\mathrm{g} / \mathrm{t}$; sc $=\mathrm{synclinal}, g=$ gauche, ap = antiplanar, $t=$ trans)

monomer unit' and 'pairing conformation' are assessable in such a straightforward way only if the constitutional periodicity of the oligomer backbone corresponds to an even number of bonds, as is the case, for example, in homo-DNA.

The analysis of the homo-DNA system (Fig. 4) reveals an ensemble of four leaststrained conformers, one of them conformationally repetitive, with the gauche-gauche $(-g /-g)$ conformation of the phosphodiester group [17]. When the latter is allowed to assume the trans-gauche conformation, there are six additional least-strained conformers, again one of them $(t /-g)$ conformationally repetitive. Therefore, a homo-DNA strand in a homo-DNA duplex can assume two types of conformations: the gauchegauche phosphodiester type with (idealized) torsion angles alpha $=-60^{\circ}$, beta $=$ $180^{\circ}$, gamma $=+60^{\circ}$, delta $=+60^{\circ}$, epsilon $=180^{\circ}$ and zeta $=-60^{\circ}$; or the trans-gauche type with alpha $=180^{\circ}$, beta $=180^{\circ}$, gamma $=180^{\circ}$, delta $=+60^{\circ}$, epsilon $=180^{\circ}$ and zeta $=-60^{\circ}$ (Fig. 4). These are exactly the two structure types that an NMR-structure analysis of the homo-d(A5T5)2 duplex has shown to co-exist in aqueous solution [18]. Duplex models, constructed out of homoDNA monomer units in either the $-g /-g$ or the $t /-g$ type of pairing conformation with all torsion angles taken to be idealized and (for the sake of argument) with all bondlengths identical, would have a linear shape; in reality, the intrinsic non-ideality of all structural parameters, assisted by the necessity of a duplex to reach optimal nucleobase stacking distances by either helicalization or by adapting axes-inclination, is bound to result in a helical twist of the duplex structure, the degree and sense of which, however, the NMR-structure analysis was unable to determine [19].

The perhaps most interesting aspect of the outcome of this kind of qualitative conformational analysis of the homo-DNA structure is the following: out of the two possible (idealized) structures of a homoDNA duplex, the $(-g /-g)$-structure, that is the one in which the (formal) nucleobase stacking distance is nearer to the optimal value, turns out to be identical in type with the structure observed by X-ray analyses as the A-type structure of DNA-duplexes
[10][18] and the structure of duplex RNA (Fig. 5). This indicates that content and outcome of the conformational analysis of the homo-DNA structure implies a rationalization of the A-type structure of DNA and, at the same time, of RNA, at the level of qualitative organic stereochemistry (Fig. 6). Furthermore, the finding that the A-type structure type of duplex DNA corresponds to a homo-DNA structure that is deduced by conformational analysis of a single strand, must mean (assuming the latter finding would still hold for a conformational analysis of a DNA single strand) that DNA (and RNA) single strands are preorganized toward duplexation. Finally, the reasoning about homo-DNA and DNA in terms of idealized conformations provides a transparent rationalization of a well known and biologically important fact, namely, that duplex DNA has the option of assuming either the A-type or its characteristic B-type structure, whereas the A-type structure is mandatory for duplex RNA (1,5- repulsion between 2 '-hydroxyl and one of the phosphodiester oxygen centers in B-type RNA; see Fig. 7) and, therefore, that DNA is 


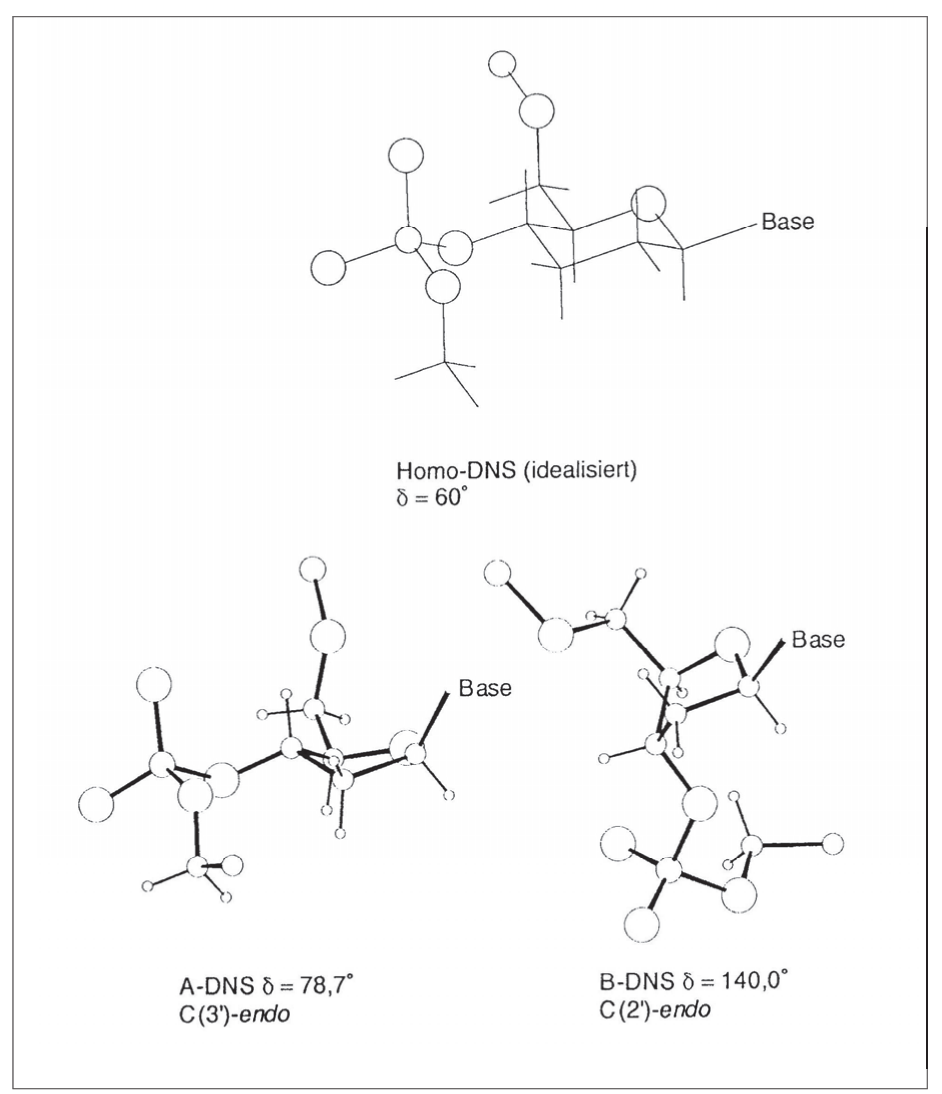

Fig. 5. Pictorial comparison of idealized $(-g /-g)$-pairing conformations of homo-DNA with experimental data of A- and B-type DNA-duplexes [1]

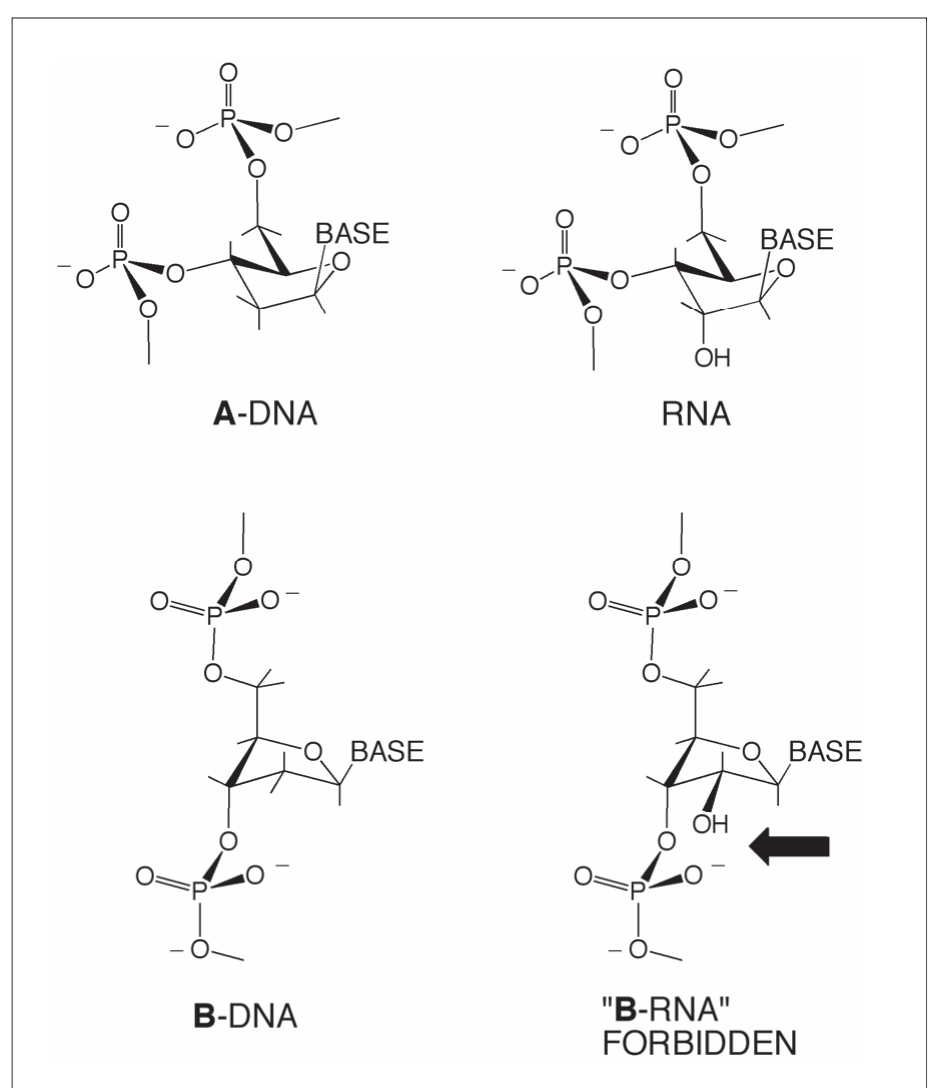

Fig. 7. When RNA crosspairs with DNA, the latter has to adapt structurally to the former and not vice versa. The steric hindrance in the (conformationally idealized) forbidden B-type RNA would consist in a repulsion between the 2 '-hydoxyl and an oxygen atom of the phosphodiester group.

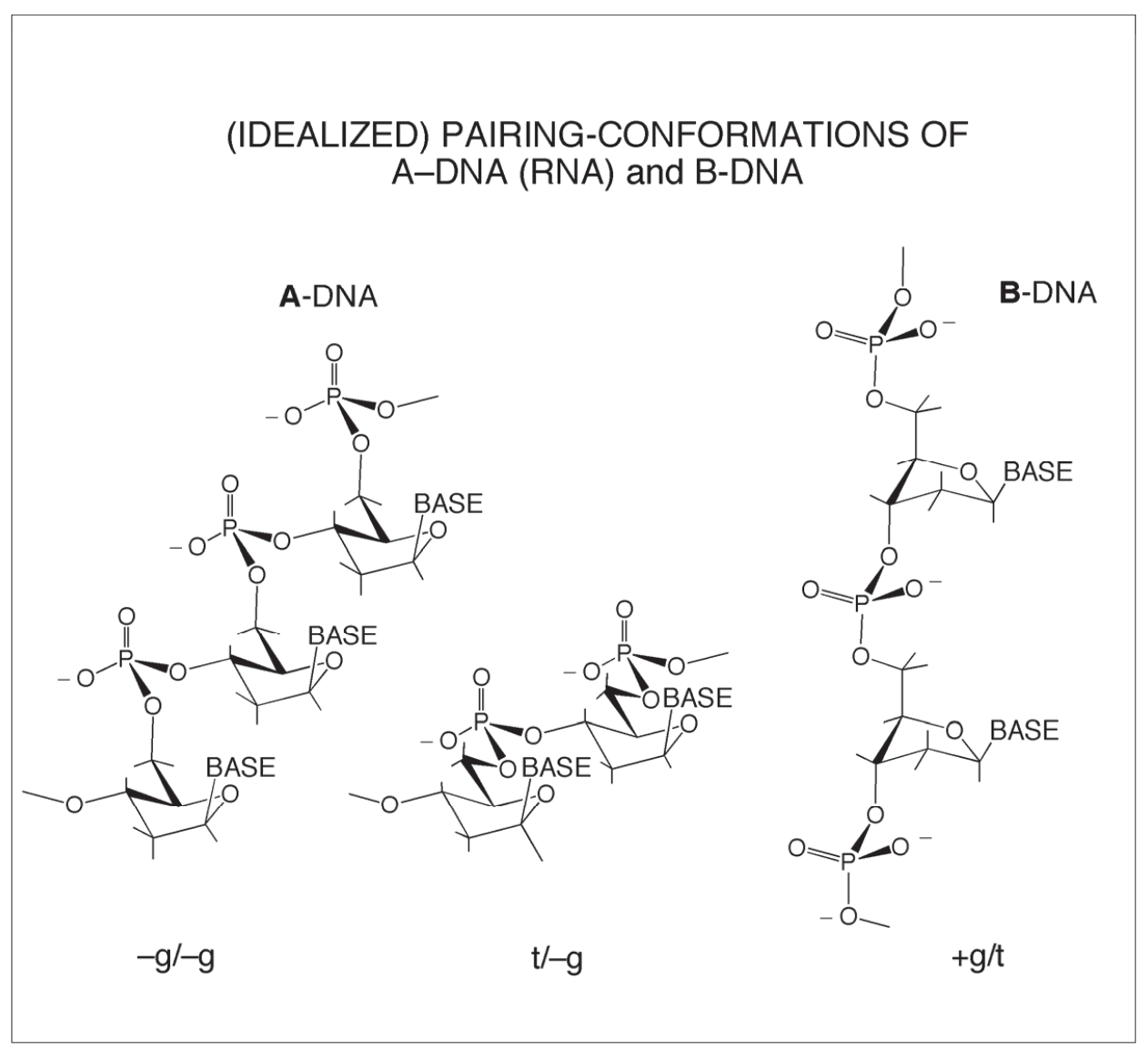

Fig. 6. On the level of idealized conformations, the sugar conformations of A- and B-type DNA duplexes are related to each other by half-chair inversions of the furanose rings forced to structurally adapt to RNA (and not vice versa) when the two are cross-pairing with each other. Analyzing and depicting the natural nucleic acids' duplex structures in terms of idealized conformations within the framework of rules listed above allows the organic chemist to rationalize and appreciate these remarkable facts at a level of stereochemical reasoning that biologists tend to achieve (Fig. 7).

The synthesis and first steps in our rather comprehensive exploration of the homo-DNA system (pioneered by Christian Leumann, Hans-Jörg Roth, Jürg Hunziker and Markus Boehringer [15][21][22]) had in our laboratory the status of a model study that served the purpose of developing experimental methodologies besides determining the influence of a simple insertion of a methylene group into DNA's furanose ring might have on the system's pairing capability. Homo-DNA was not considered to be a potentially natural nucleic acid alternative because the dideoxy-hexose sugar building block is a generationally much more complex sugar in comparison to a non-reduced hexose; it is in this sense that the homo-DNA project represented only a model study.

The base-pairing properties of synthetic homo-DNA strands turned out to be remarkable, to say the least. Strands with comple- 
mentary nucleobase-sequences showed regular Watson-Crick pairing much stronger than in DNA, but did not display any cross-pairing with complementary DNA (or RNA) strands. In homo-DNA, there is strong purine-purine pairing of guanine with isoguanine and of 2,6-diaminopurine and xanthine in the Watson-Crick mode, as well as homo-purine-purine self-pairing of adenine and of guanine in the reverse-Hoogsteen mode. Comparison of thermodynamic parameters of homo-DNA and DNA duplexations clearly revealed homo-DNA's stronger Watson-Crick pairing to be of entropic rather than enthalpic origin and, therefore, to presumably reflect a higher degree of conformational strand preorganization toward duplex formation in homo-DNA than in DNA, very plausibly so, considering the difference in flexibility between a pyranose chair and a furanose ring (Fig. 8).

It was Christian Leumann who first drew the consequences of these observations by initiating and pioneering with his 'bicycloDNA' project [23] an important strategy in anti-sense oriented nucleic acid research (design of oligomer backbones that are conformationally preorganized toward duplexation with DNA and RNA), a strategy that turned out to be highly successful in his and a number of other laboratories (Fig. 9) $[2 d][24]$.

Fig. 10 gives - in terms of the formulae of monomer units depicted in their (potential) pairing conformation - an overview of all the families of nucleic acid alternatives we investigated at ETH and TSRI, all (except homo-DNA) taken from the close structural neighborhood of RNA and deemed to be potentially natural nucleic acid alternatives since they relate generationally to their respective building blocks in the same way as RNA does to ribose, purines, pyrimidines, and phosphate. Colored formulae denote oligomer systems found experimentally to be Watson-Crick basepairing systems, identical color indicates systems that are capable of communicating with each other through informational intersystem cross-pairing, non-colored members denote oligomer systems that are devoid of any significant base-pairing capability in the Watson-Crick mode.

A remarkable and etiologically significant finding is the discrepancy between the base-pairing potential of the model system homo-DNA and the three studied members of the family of homo-DNA's 'natural' ana$\operatorname{logs}$, namely, the fully hydroxylated oligonucleotide systems derived from allose, altrose and glucose [11-13]. The latter show neither efficient, nor consistent WatsonCrick base-pairing. Exploratory base-pairing tests with mono-hydroxylated models of the allose- and altrose-derived oligomers supported the hypothesis that the source of

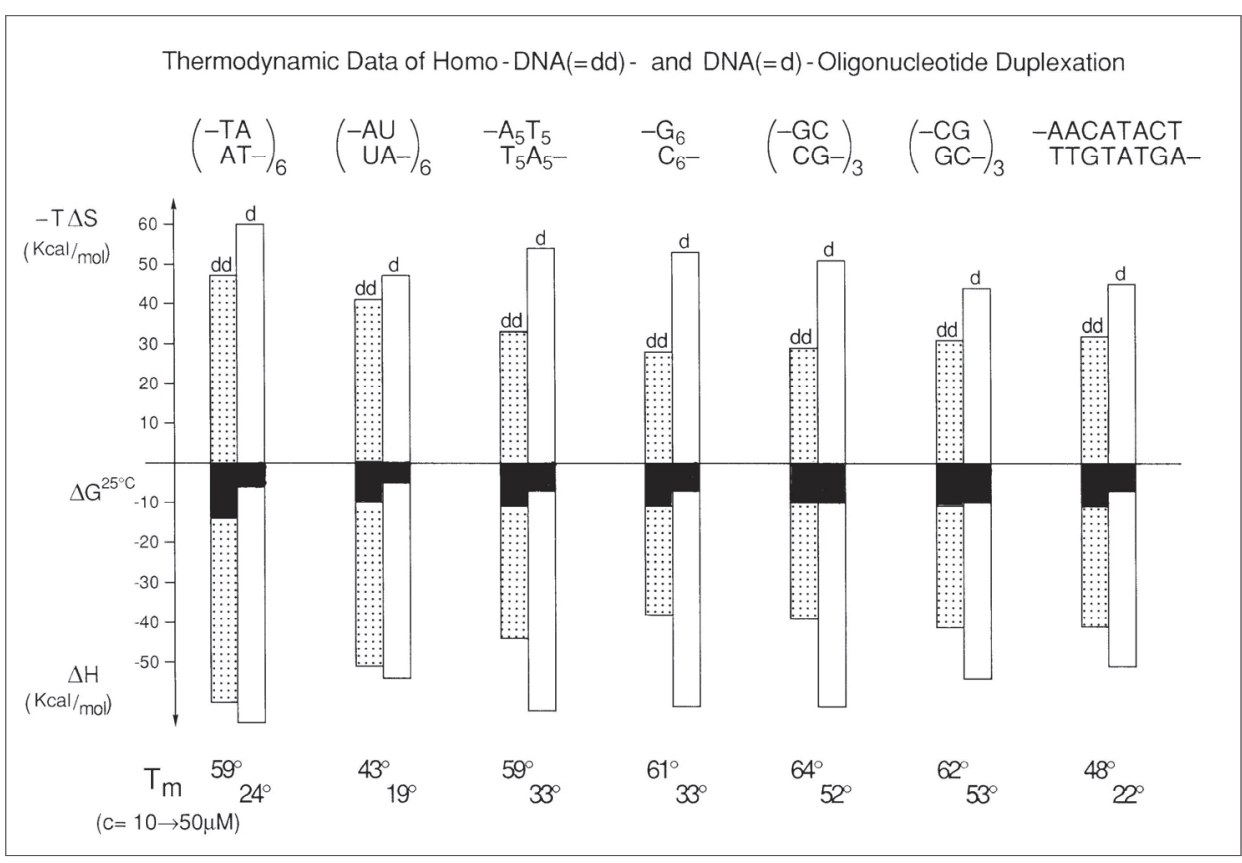

Fig. 8. Comparison of thermodynamic data of duplexations in the homo-DNA versus the DNA series [15]. The larger negative delta-G values of the homo-DNA duplexations are entropic in origin. HomoDNA single strands are more strongly preorganized toward duplexation than RNA single strands, and the latter (see Fig. 7) more strongly than DNA single strands.

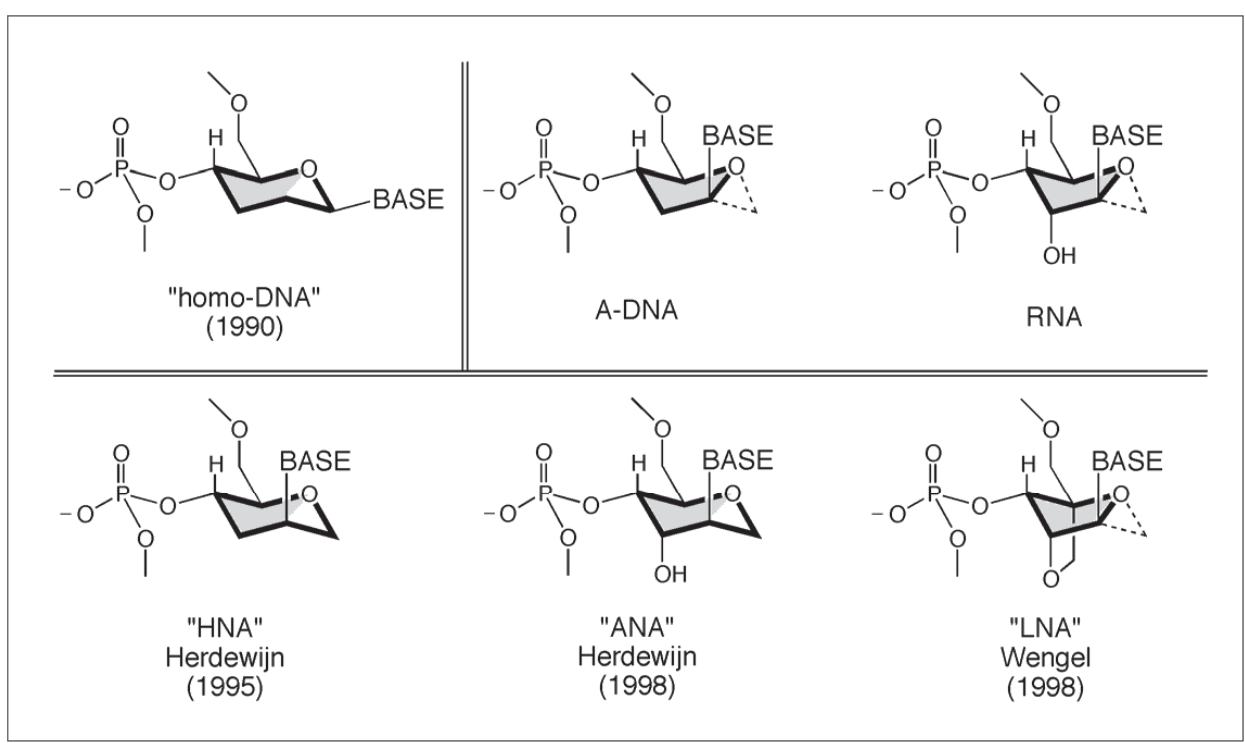

Fig. 9. Pictorial juxtaposition (in the form of idealized conformations) of homo-DNA with the natural systems and important analogs of the latter (for these analogs see [24])

this crucial difference in pairing capability is steric hindrance involving the two additional hydroxyl groups of the fully hydroxylated hexopyranose unit, as well as neighboring nucleobases, precluding the population of the unit's pairing conformation in oligomers [25]. Clearly, RNA-alternatives derived from hexopyranoses in place of ribofuranose could not have acted as functional competitors of RNA in Nature's evolution of a genetic system [26].

Apart from homo-DNA, by far the most extensive of our experimental efforts invested in the nucleic acid etiology project was directed to the synthesis (pioneered by
Stephan Pitsch and Sebastian Wendeborn [27]) and investigation of the structure and properties of the pyranosyl isomer of RNA $(=$ 'p-RNA'), the nucleic acid alternative that is composed of the very same building blocks as natural RNA itself. In contrast to the backbone design for RNA-alternatives in the hexopyranosyl series where the phosphodiester group can link the sugar units in a way completely analogous to that in RNA (4'-6'-link in hexopyranose and $3^{\prime}-5^{\prime}$-link in ribofuranose), the design of the backbone of a pyranosyl-RNA demanded a distinct deviation from that constitutional pattern in as far as a 6-bond periodicity of the pento- 


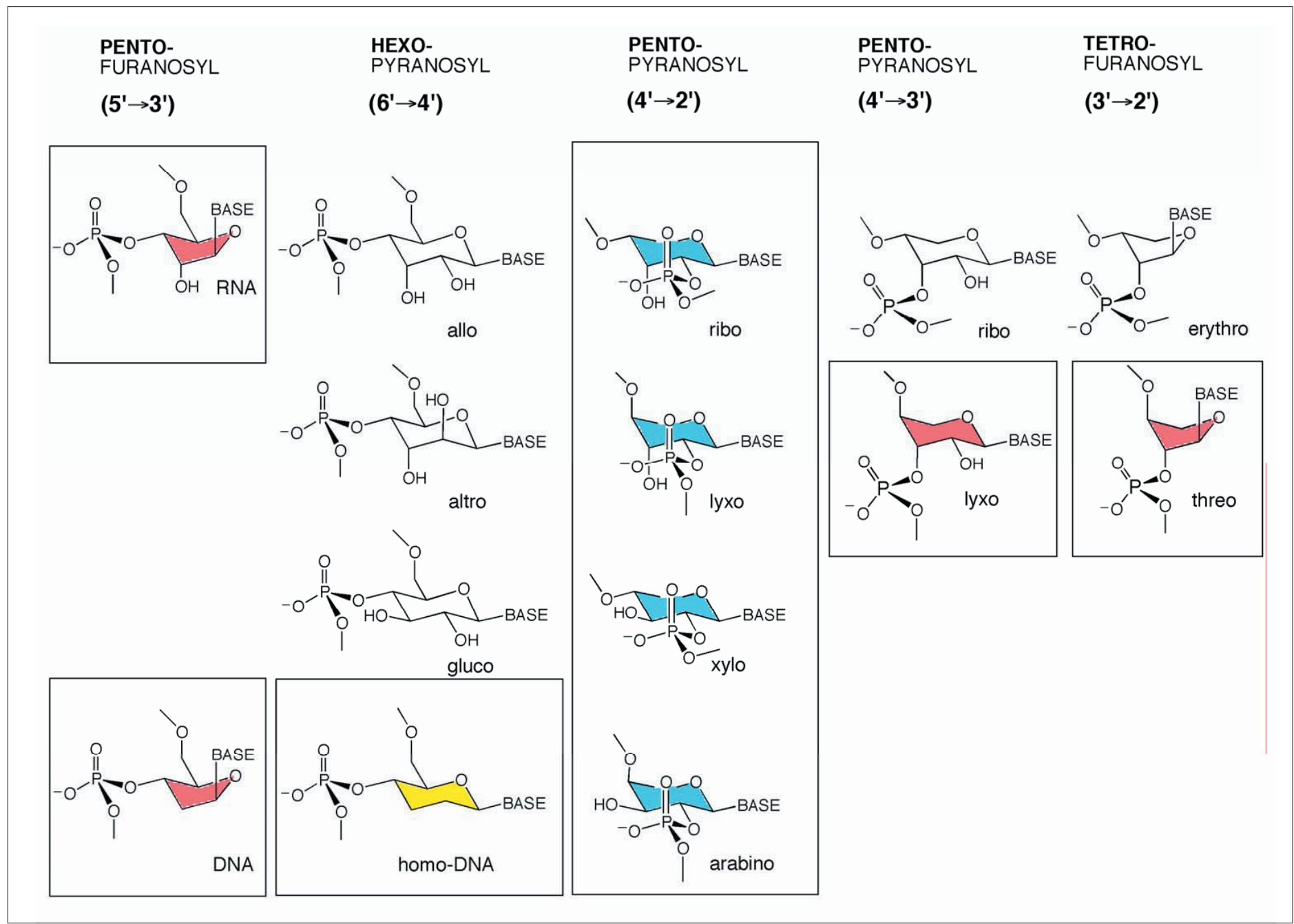

Fig. 10. Overview of the families of nucleic acid alternatives investigated at ETH and TSRI (same color denotes Watson-Crick base-pairing in the same base-pairing language; absence of color indicates lack of or only weak Watson-Crick base-pairing capability)

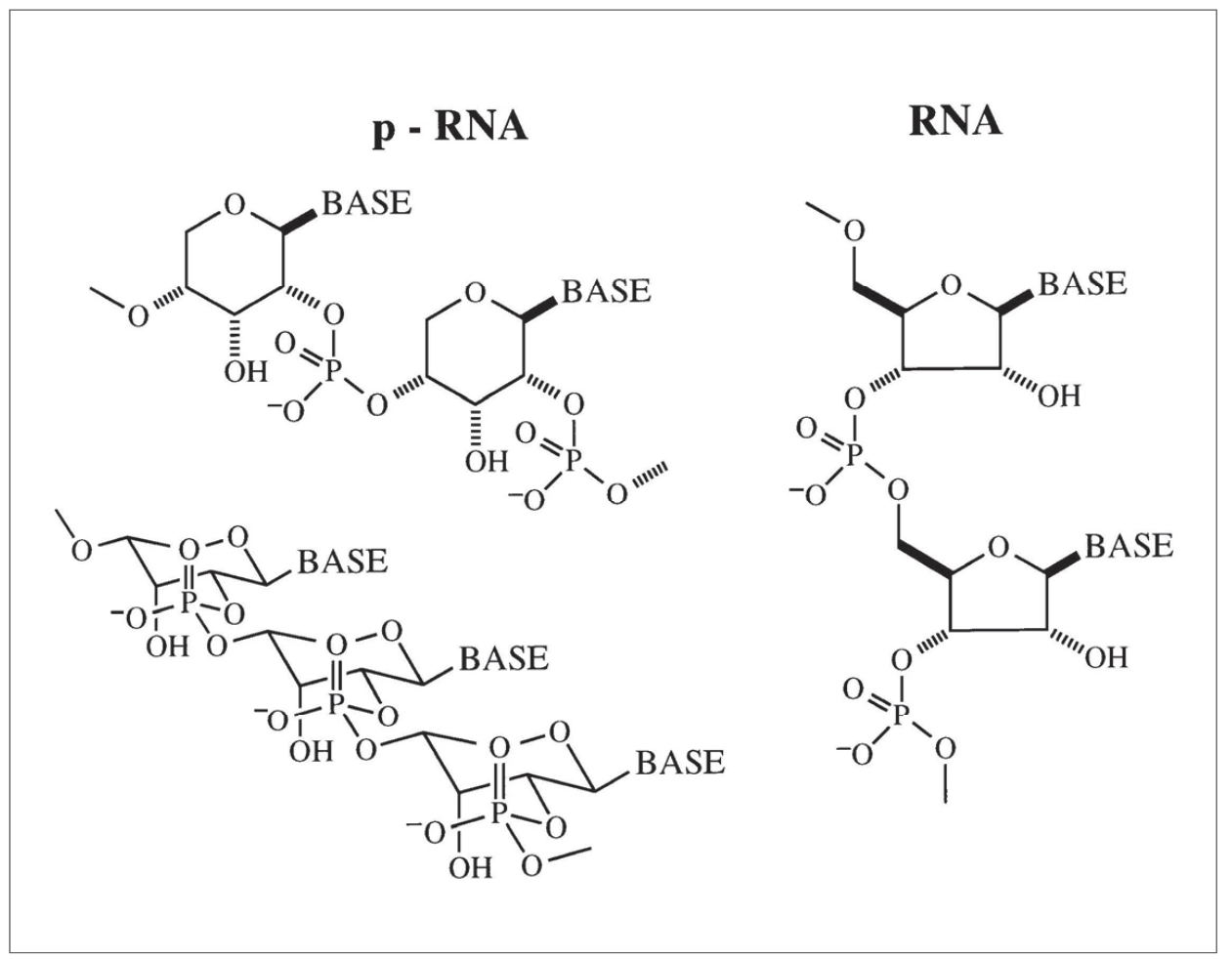

Fig. 11. Constitution and pairing conformation of pyranosyl-RNA pyranose backbone would only be compatible with a $\left(2^{\prime}-4^{\prime}\right)$-phosphodiester junction. Applying this criterion and defining the nucleoside to have the beta-configuration (in order to have the nucleobase at the ribopyranose chair in an equatorial position) resulted in the p-RNA backbone depicted in Fig. 11. p-RNA's pairing conformation, equally depicted in Fig. 11, emerged in a remarkably unambiguous way from a conformational analysis carried out with the very same criteria used already for homo-DNA: the ensemble of nine least-strained monomer-unit conformers contains only a single member displaying a repetitive conformation and, therefore, embodying the pairing conformation of an p-RNA duplex (Fig. 12). It was not only this singularity that allowed us to predict with high confidence that p-RNA will turn out to be a base-pairing system, it was above all our experience that the pairing model for homo-DNA, built with the same criteria as that of p-RNA, had in fact found its counterpart in reality and, therefore, there was reasoned hope that the p-RNA model would do so, too. In fact, the agreement between the predicted model 


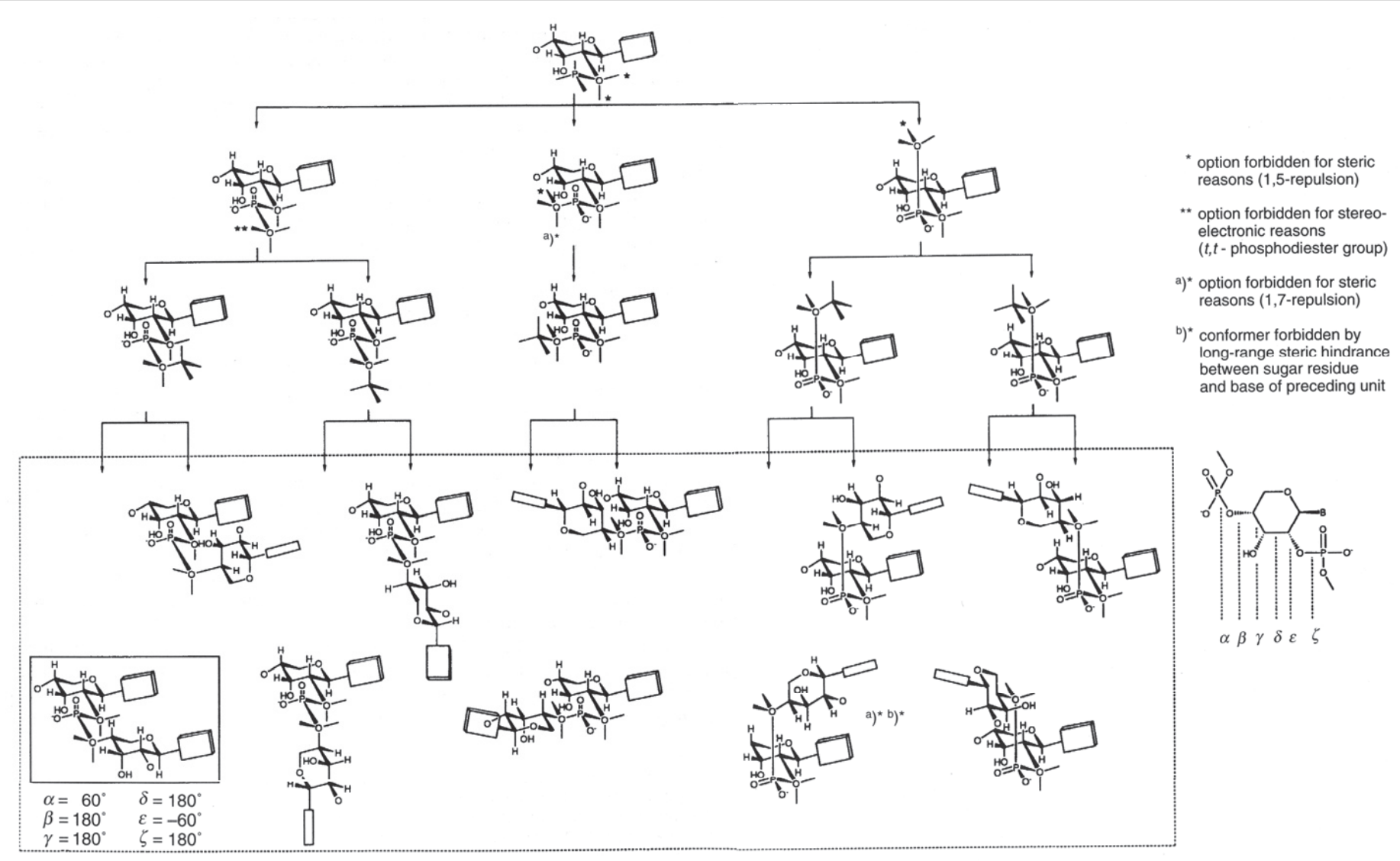

Fig. 12. Qualitative conformational analysis of pyranosyl-RNA (facsimile from [27a])

and the model that emerged from Bernhard Jaun's X-ray analysis and Romain Wolf's molecular mechanics-based modeling of the p-RNA-octamer duplex pr(CGAATTCG) ${ }_{2}$ was exquisite [28].

While such unambiguous agreement between 'theory' and experiment is of course welcomed, it is to encounter clearcut disagreement with specific details of a 'theory's' predictions that reveals to us the limits of that 'theory' and, therefore, should to be welcomed, too. We encountered such disagreement when we studied the entire family of the four possible diastereomeric pentopyranosyl-oligonucleotide systems (containing equatorial nucleobases) [29], namely, (besides the beta-D-ribo-system) the beta-D-xylo- [30], the alpha-L-lyxo[31], and the alpha-L-arabino- [32] member (Fig. 13). It was the arabinopyranosyl member that turned out to be the strongest base-pairing system by far of the entire

\section{Pento-pyranosyl-(4' $\rightarrow$ 2')-oligonucleotides}

\section{(with equatorial nucleobases)}
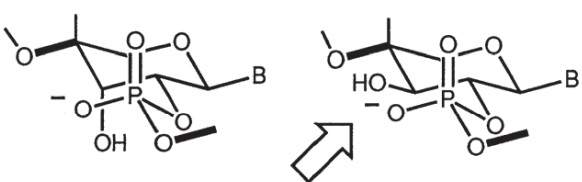

(D)- $\beta$-Ribo-
(D)- $\beta-X y l o-$
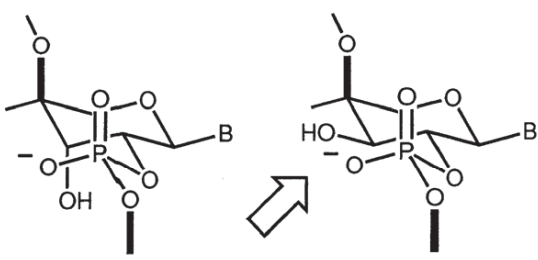

(L)- $\alpha-$ Lyxo-
(L)- $\alpha$-Arabino- family (Fig. 14), while we had expected it to be a member that would definitely pair less strongly than p-RNA [27a].

The alpha-L-arabino-pyranosyl system is, in fact, one of the strongest oligonucleotide-type Watson-Crick pairing systems known today. The lesson which this discrepancy between expectation and fact taught us was (at least) two-fold: First, in cases where the conformational analysis in terms of idealized conformations leads to an ensemble of monomer-unit conformers in which - according to the standard criteria - all members (the conformationally repetitive one(s) inclusive) are heavily strained, the task of judging on the level of idealized conformations as to whether a conformationally repetitive conformer is among the least unstable conformers is no longer straightforward, neither is, therefore, any prediction with regard to such a system's base-pairing capability. Second, the relative base-pairing strength of a system is intrinsically co-determined by intermonomer-unit-repulsions that are not taken into account by the routine analysis of the monomer unit conformations. However, the perhaps major lesson that our study of the pentopyranosyl-oligonucleotide family as a whole taught us, was the one given by the alpha-L-lyxopyranosyl system [29][31]; it was the lesson that determined the next
Fig. 13. The four diastereomeric pentopyranosyl-RNA variants (with equatorial nucleobases) studied at ETH and TSRI. Arrows point to severe steric hindrance in (idealized) pairing conformation. 


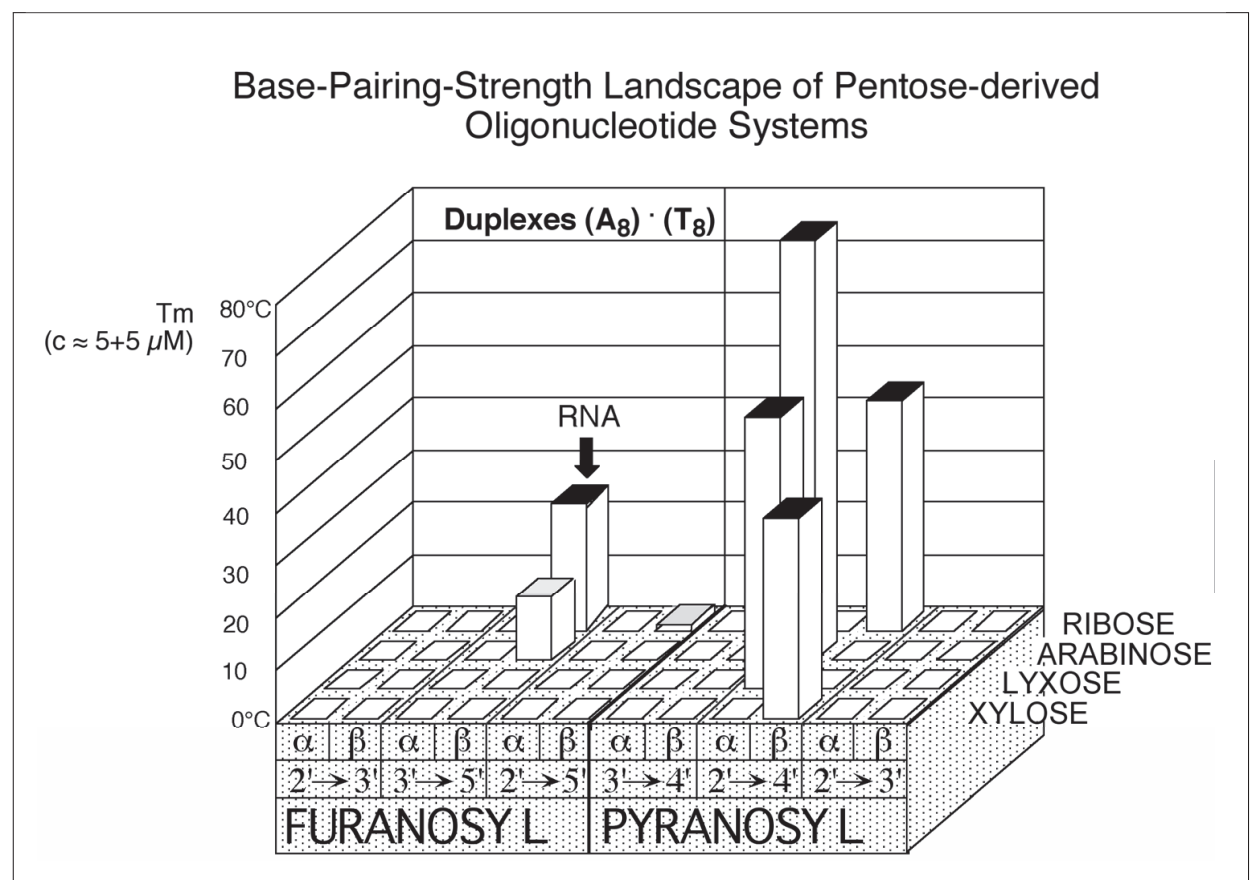

Fig. 14. Comparison of base-pairing strength of pentopyranosyl-oligonucleotides and RNA $\left(A_{8} / T_{8}\right.$ duplexes; in 0,15 M NaCl, $10 \mu \mathrm{M} \mathrm{NaH}{ }_{2} \mathrm{PO}_{4}, \mathrm{pH} 7$; see [27][29-32])

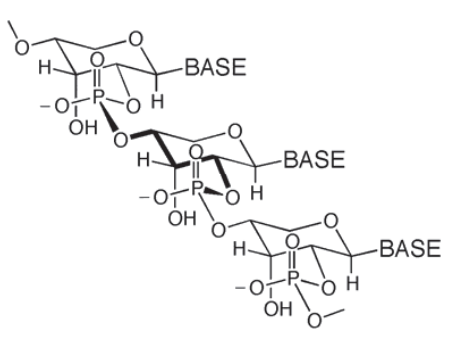

(D)- $\beta$-ribopyranosyl $4^{\prime} \rightarrow 2^{\prime}$

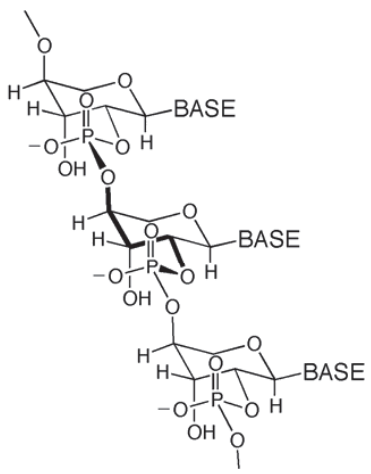

(L)- $\alpha$-lyxopyranosyl 6 bonds per
backbone unit

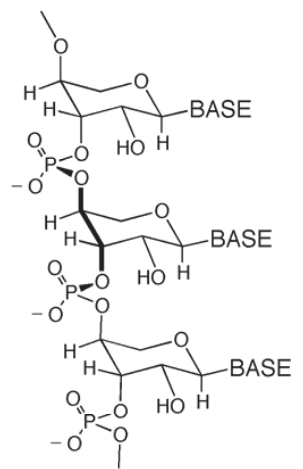

(D)- $\beta$-ribopyranosyl

$$
\begin{array}{ll}
4^{\prime} \rightarrow 3^{\prime} & \begin{array}{l}
5 \text { bonds per } \\
\text { backbone unit }
\end{array}
\end{array}
$$

\section{(L)- $\alpha$-lyxopyranosyl}

project in our work and came about as follows.

One of the most remarkable properties observed for pyranosyl-RNA was its capacity for template-controlled ligations, especially the capability of hemi-selfcomplementary p-RNA-tetramer- $2^{\prime}, 3^{\prime}$-cyclophosphates to regio-and chiroselectively self-template their gradual growth into duplexes of long complementary p-RNA sequences (pioneered by Stephan Pitsch and Martin Bolli [33][34]). The study of this type of ligation chemistry demanded a careful proof of its regioselectivity, in connection of which iso-p-RNA-oligomers with $\left(3^{\prime}-4^{\prime}\right)$ - instead of $\left(2^{\prime}-4^{\prime}\right)$-phosphodiester bridges were synthesized for comparison purposes (Fig. 15). Not unexpectedly, such isomeric p-RNA-strands lacked the capability of either intra-system or intersystem (with DNA) base-pairing (fivebonds periodicity). However, the analogous modification in the alpha-L-lyxopyranosyl series, in which a $\left(3^{\prime}-4^{\prime}\right)$-phosphodiester bridge is diaxially attached to the pentopyranosyl chairs, produced oligomer strands that, though not completely unexpectedly, revealed themselves as being capable of intra-system base-pairing and, surprisingly, of inter-system cross-pairing with DNA. It seemed clear that the reason for such a drastic six-bond-rule disdaining behavior must be lying in the unique trans-diaxial arrangement of the phosphodiester bridge [35].

Sugar units consisting of tetroses (which can form only furanoses) had originally been explicitly neglected as building blocks of nucleic acid alternatives because it is not possible to derive from them tetrofuranosyl-oligonucleotides with a backbone periodicity of six bonds. Our observations with the lyxopyranosyl system made us, however, rethink the matter and etiology-driven reasoning quickly associated the structure of an alpha-L-threo-furanosyl-oligonucleotide strand in which the trans-phosphodiester bridge might be held in quasi-diaxial conformation by electrostatic reasons and, therefore, give rise to a behavior similar to that of an alpha-L-lyxopyranosyl oligonucleotide strand (Fig. 16). Why should such a system be of etiological interest? It would be very much so, because the four-carbon sugar threose is a generationally simpler sugar than ribose.

Alpha-L-threofuranosyl-oligonucleotides ('TNA', Fig. 17; pioneered by Uwe Schönig and Peter Scholz [36]) turned out to be a marvelous Watson-Crick base-pairing system of a pairing strength comparable to that of RNA and the capability to cross-pair with equal efficiency with the natural system (Fig. 18). Bernhard Jaun's NMR-structure analysis of the duplex $\mathrm{t}(\mathrm{CGAATTCG})_{2}$ showed an RNA-like right-handed helix [37], and Martin Egli's
Fig. 15. $\left(4^{\prime}-2^{\prime}\right)$ - versus $\left(4^{\prime}-3^{\prime}\right)$-phosphodiester bridges in the pentopyranosyl RNA series 


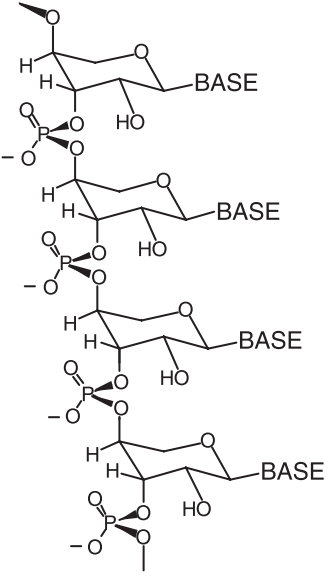

(L)- $\alpha$-LYXO-PYRANOSYL

$\left(4^{\prime} \rightarrow 3^{\prime}\right)$

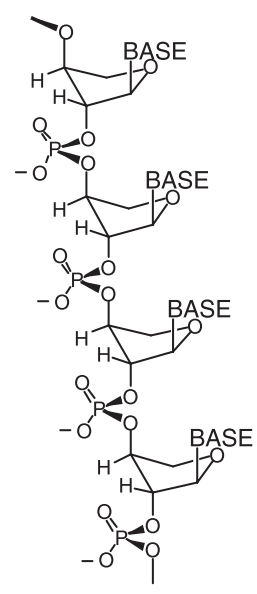

(L)- $\alpha$-THREO-FURANOSYL $\left(3^{\prime} \rightarrow 2^{\prime}\right)$

Fig. 16. The conceptual leap from observing the properties of the $\left(4^{\prime}-3\right)$ lyxopyranosyl system to studying the (3'-2')-threofuranosyl system

two X-ray structure analyses of both an Aand B-type DNA duplex of a self-complementary dodecamer sequence containing a single TNA-unit demonstrated how the quasi-diaxial phosphodiester bridge adjusts to the DNA double helix, revealing at the same time TNA's distinct preference for the A-type structure paralleling the observation that TNA cross-pairs more strongly with RNA than with DNA [38].

Among molecular biologists, TNA has become more popular than, e.g. the pyranosyl isomer of RNA, this as a simple consequence of the fact that TNA does not speak a 'foreign' language as p-RNA does. In Jack Szostak's laboratory it was shown that TNA strands in the presence of a 'tolerant' DNA-polymerase can template DNA-synthesis and, most remarkably, DNA strands can serve as template for the faithful synthesis of complementary TNA- strands (so far up to 50-mer) from alpha-Lthreofuranosyl-nucleotide-2'-triphosphates [39]. The authors of these findings consider such experiments as first steps in a project that aims at an in vitro evolution of TNA (with the help of contemporary enzymes) to the functional level of an artificial genotype possessing phenotypic properties. The model vision behind this work is the role assigned to RNA in a hypothetical world (the 'RNA-world'), considered to have preceded our own, in which RNA is thought to have fulfilled both genotypic and phenotypic functions [40].

Can the structural and generational simplicity of an informational oligomer system such as TNA be pushed even further? In one of our papers [35], we had commented on such an extrapolation of the TNA structure to an even simpler system by hypothesizing that acyclic phosphodiester-based oligomers of the type depicted in Fig. 19 might prove to behave like TNA since the trans-antiperiplanar arrangement of the negatively charged phosphodiester groups - a violation of the gauche effect notwithstanding - might be favored by electrostatic repulsion. We refrained from testing the hypothesis experimentally because we supposed the simplicity of oligomers, such as the one derived from the C3-backbone $(\mathrm{n}=$ 1 ), is deemed to be structural and not generational (its backbone unit corresponds to a reduced sugar) and, therefore, to be a system that lacks the attribute of being poten-

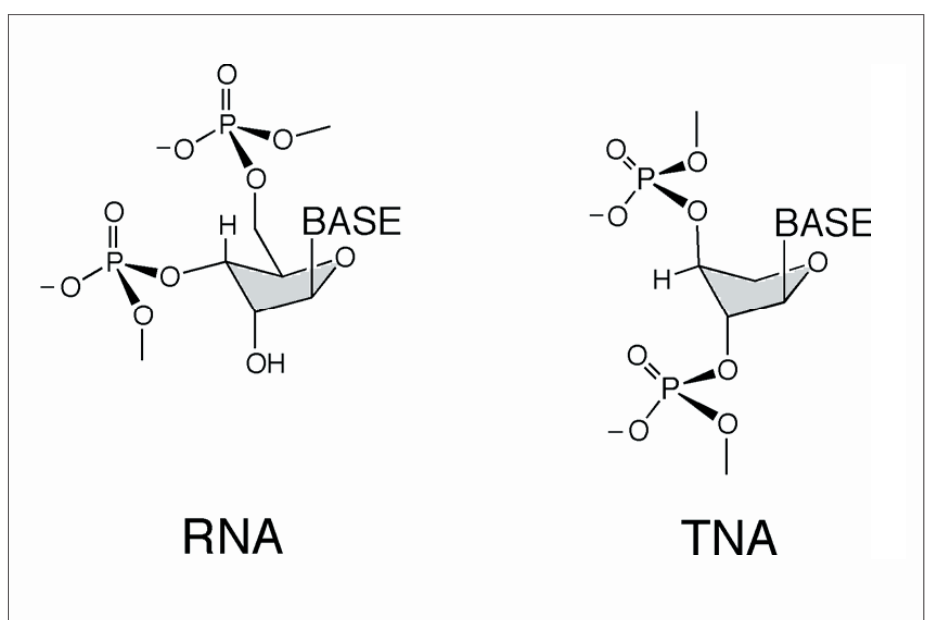

Fig. 17. Juxtaposition of the (idealized) pairing conformations of RNA and TNA

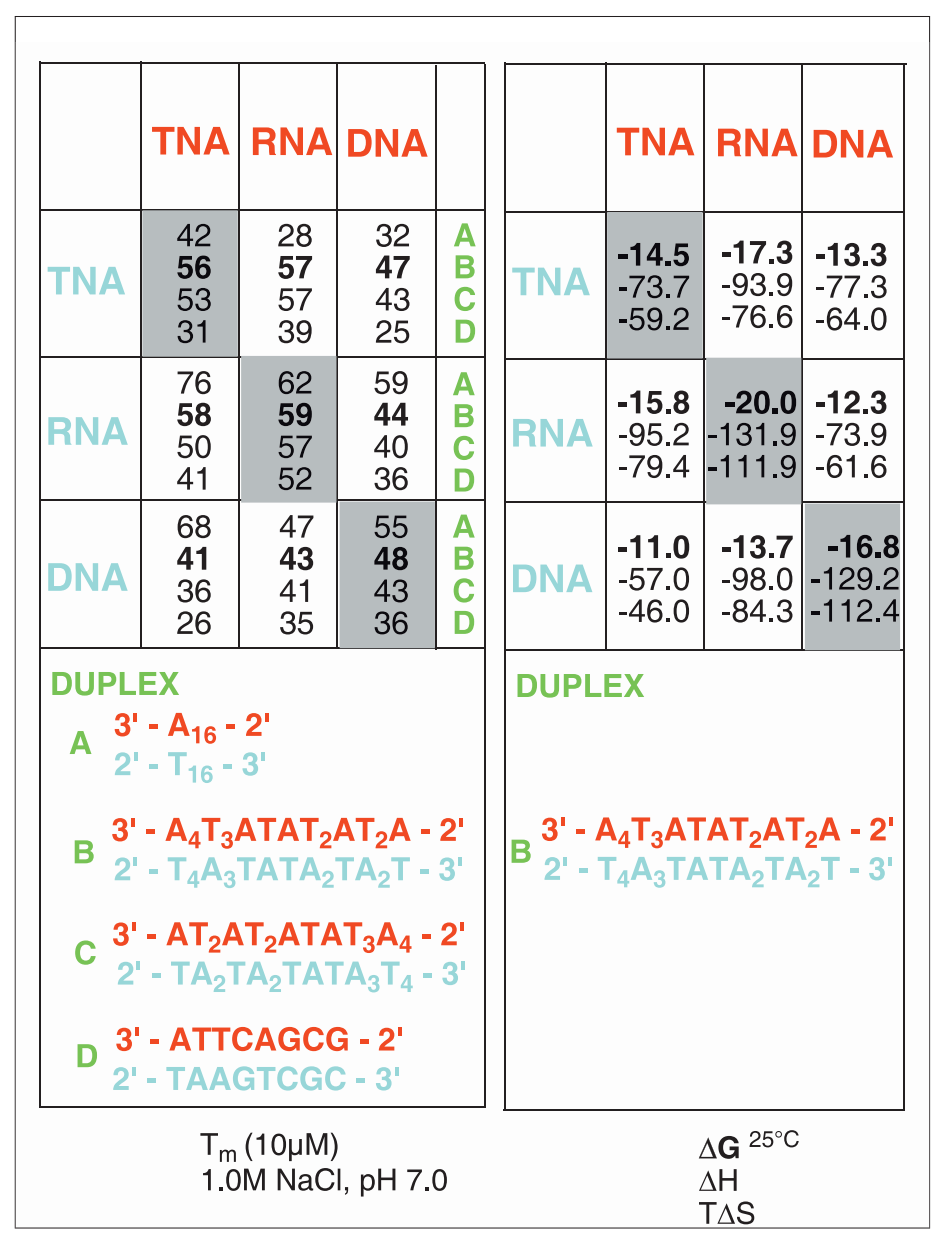

Fig. 18. $T_{m-}$ values and thermodynamic data of self- and cross-pairing in duplex formation within and in between the TNA-, RNA- and DNA-series [36] 


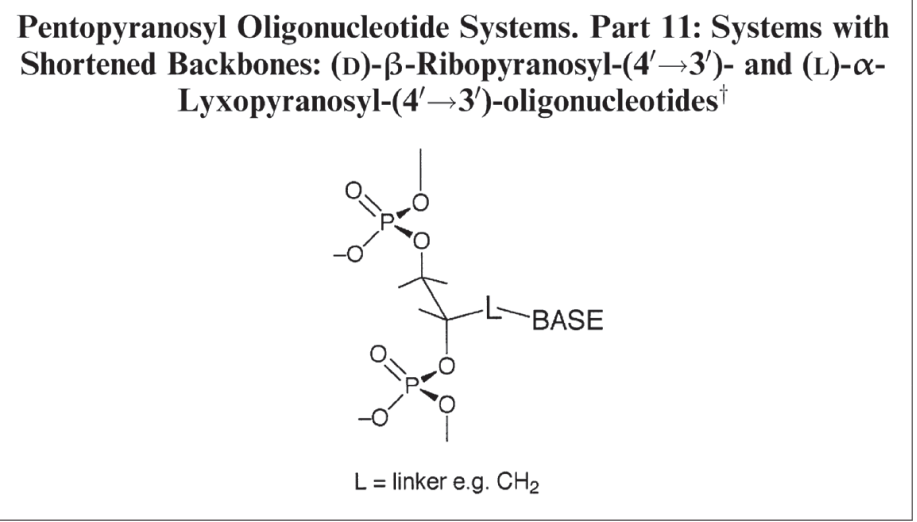

Fig. 19. A hypothetical aliphatic oligonucleotide backbone system in which the vicinal phosphodiester groups might - as a result of a tendency to minimize electrostatic repulsion - assume an antiperiplanar conformation (excerpt from [35])

tially natural. Fortunately for nucleic acid chemistry, such a constraint is not what everybody adheres to, and so we know today, thanks to recent work by Eric Meggers [41], that the $(n=1)$-oligomer of Fig. 19 is an impressively efficient base-pairing system, able to cross-pair with the natural nucleic acids.

The available NMR-structure analyses for duplexes of the homo-DNA- [18], pyranosyl-RNA- [28], arabinopyranosylRNA- [42] and TNA- [37] series revealed structural models that fall into three different groups where the degree and orientation of the inclination between the (averaged) backbone axis and the (averaged) base-pair axis [43] is concerned. The ladder-like, feebly helical models of homo-DNA and the two pentopyranosyl-nucleic acids show a strong inclination of these axes, yet - significantly - in opposite orientation [43], whereas the compactly helical model of TNA resembles the right-handed helices of the natural nucleic acids of which, characteristically, the B-type helix of DNA has essentially no inclination. This difference in degree and orientation of backbone inclination is related to the base-pairing orthogonality of the three groups of nucleic acid (Fig. 20), giving rise to barriers to conformational adjustments necessary for base-pairing, even though the inclination is (formally) efficiently adjustable through rotation around nucleosidic bonds (Fig. 21) [35]. The degree of inclination of these axes (in any orientation) correlates with two further structural properties of informational oligomers: one is a system's propensity to pair in parallel, versus antiparallel, strand orientation [15], and the other the nature of the base-stacking in duplexes, namely, intra-versus inter-strand [28][42][43]. The more strongly inclined a system's backbone is, the more strongly forbidden is base-pairing in parallel strand

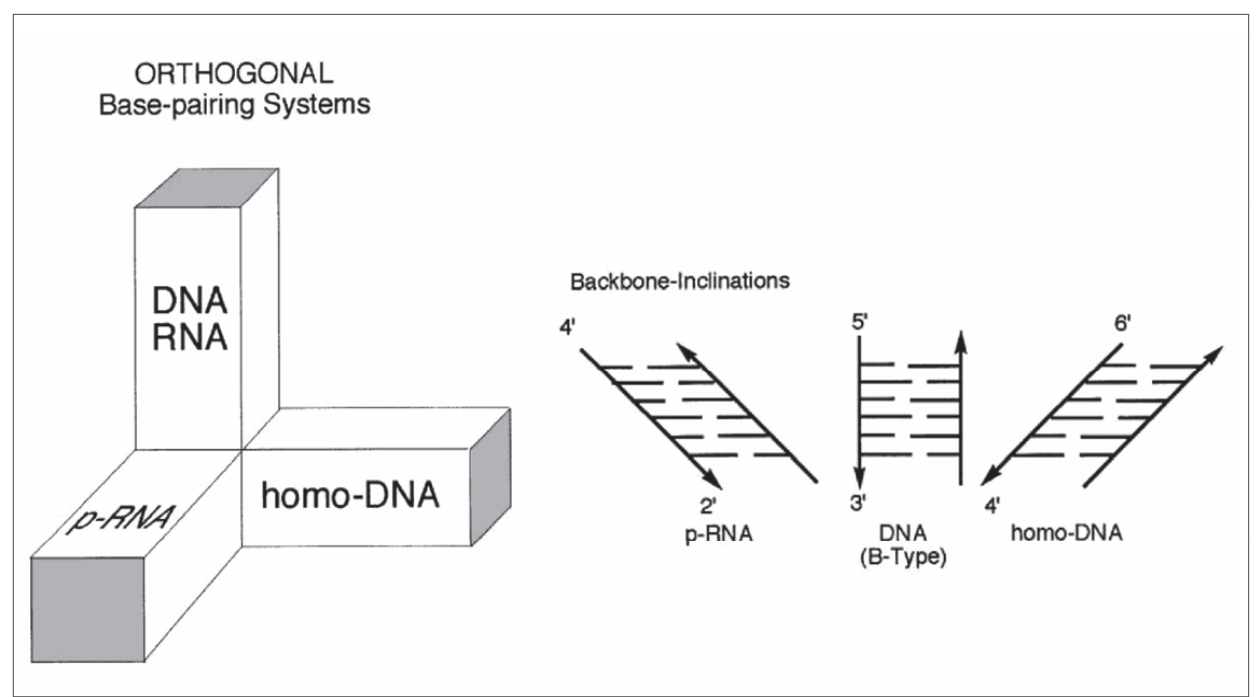

Fig. 20. The three groups of base-pairing systems which exhibit strong intrasystem base-pairing but do not cross communicate with each other; they represent orthogonal base-pairing systems. This orthogonality is proposed to be related to the different backbone/base-pair-axes inclinations of these systems (excerpt from [35]).

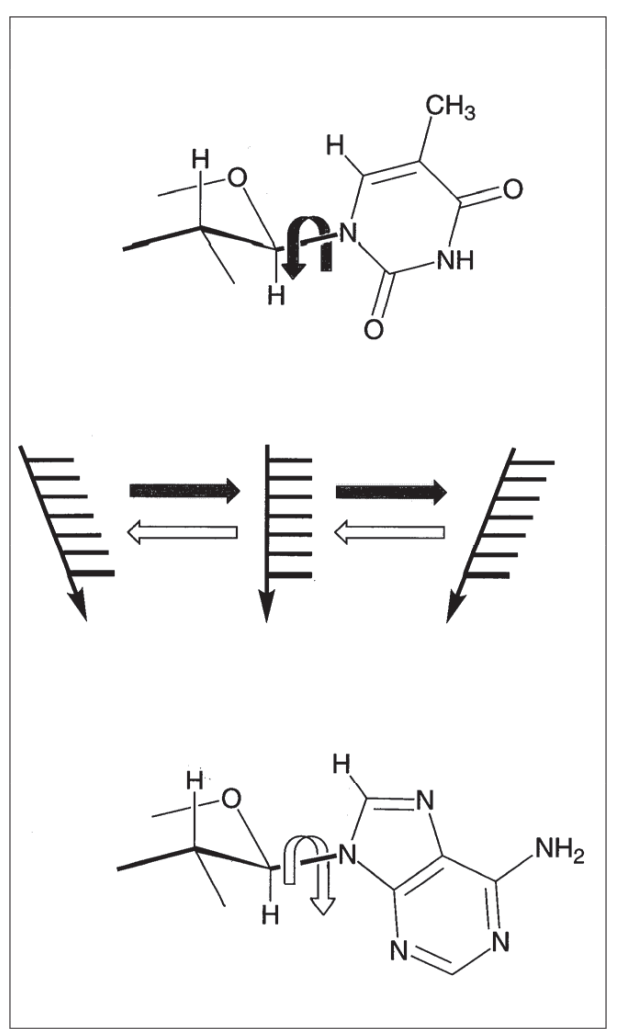

Fig. 21. Rotation around the nucleosidic bonds in oligonucleotides changes the inclination between the (averaged) backbone-basepair axes (rotation in the sense indicated by the picture on the top induces an inclination shift towards the right)

orientation, and the more pronounced interstrand is the base-stacking.

Have we reached the boundaries of the structural landscape of the carbohydrate derived phosphodiester type base pairing systems by what we know today? The answer is a clear " $n o$ " from a purely chemical point of view, and a cautious "very probably not" when referring to systems that fall into the category of potentially natural nucleic acid alternatives. What at this stage, however, seems more urgent than to go on and close this remaining gap of knowledge may be to abandon the selection criterion that determined the course of our work so far, namely, that the structure of nucleic acid alternative has to be taken from RNA's structural neighborhood in the sense that it must be derivable from a $\left(\mathrm{CH}_{2}\right)_{\mathrm{n}}$ aldose sugar by the same type of generational chemistry that allows the structure of RNA to be derived from ribose. There is that other class of fundamental biomolecules, the polypeptides and proteins, whose backbone can also serve - as recent work on nucleobase-tagged peptide-like oligoamide backbones has amply shown [6][8][44-52] - as the skeleton of informational oligomers. The polypetide instead of oligonucleotide type of structure could serve as reference in a search for nucleobase-tagged oligomers, whose repeating units would have 
to be tagged dipeptide units, as recognized at the very beginning of our work [4][6]. We would again demand candidate structures to be potentially natural in the sense that they have to be derivable from their building blocks by the same type of basic chemistry that connects polypeptides with the proteinogenic alpha-amino acids and, moreover, that these nucleobase-tagged building blocks should be derivable from natural alpha-aminoacids by potentially primordial reactions.

The last section of this article deals with the question as to what extent the kind of conformational reasoning used in the search for oligonucleotide type nucleic acid alternatives could assist such a search in the field of nucleobase-tagged oligo-dipeptides and related systems and, moreover, could provide a qualitative rationalization of the facts already known in this field.

Fig. 22 recapitulates the two types of (idealized) pairing conformations of the repeating monomer unit of homo-DNA, transcribed into the corresponding formulae of DNA (and RNA) backbones (see also Fig. 6), the (-g/-g)-variant of the two representing the type of conformation characteristically observed for A-type duplexes of DNA and RNA. Important characteristics of this backbone conformation are the two 180 degrees torsion angles beta and epsilon (bonds in red color). In a further transcription of the conformation into a backbone variant that lacks the cyclic part of the natural systems, the red-colored bonds of the backbone formula define the positions at which double bonds could be accommodated without changing in any major way the overall shape of the backbone thread (Fig. 23, formula a) [53]. Interestingly, the relative positions of these double bonds correspond to the relative positions of the (planar) amide bonds in oligopeptides. This means that this specific (idealized) type of polypeptide backbone conformation corresponds to the $-g /-g$ pairing conformation of the backbone in A-DNA (and RNA), and that nucleobase-tagged oligo-dipeptides, depending on the structural details of the nucleobase-bearing chains alternatingly attached at tetrahedral positions of the backbone (see below), may represent systems that harbor the capacity of base-pairing with themselves and of cross-pairing with DNA and RNA.

As Fig. 23 (formula b) indicates, there is another way of maintaining the conformational character of the A-DNA type backbone within an aliphatic backbone thread, namely, by putting electronegative atoms at the positions labeled in the Fig. as black spots. If such a backbone were to follow the organic chemist's 'gaucheeffect' in choosing its preferred confor-

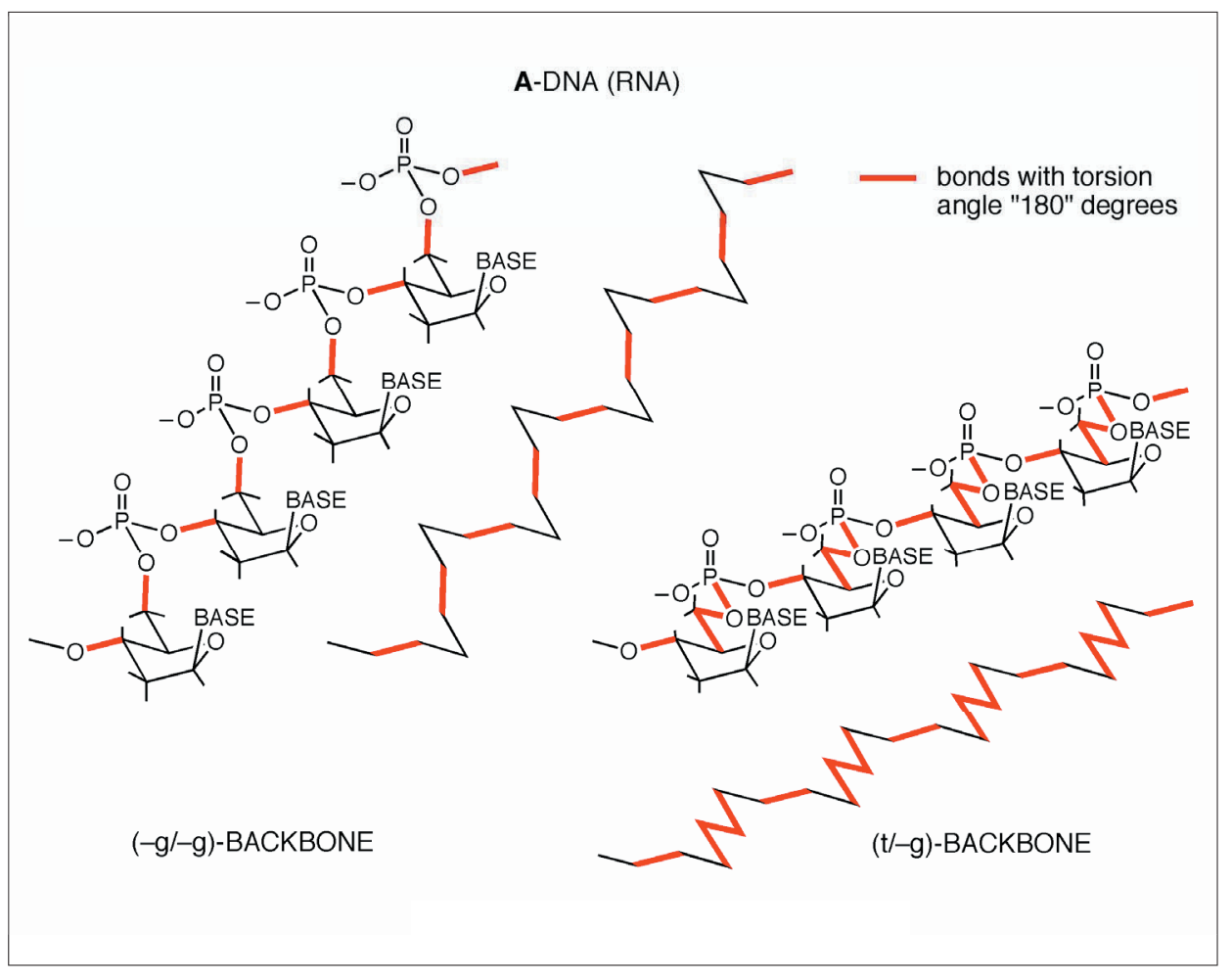

Fig. 22. The two 'allowed' pairing conformations of homo-DNA transcribed into the formula of A-type DNA (or RNA). Bond symbols in red denote backbone torsion angles of 180 degrees. The thread in the middle of the figure depicts the backbone-core of the $(-g /-g)$-conformer of A-type DNA. The thread conformation that corresponds to the $t /-g$ conformation (lower right) happens to be identical to the conformation of the thread that would correspond to the (idealized) B-DNA conformation depicted in Fig. 6.

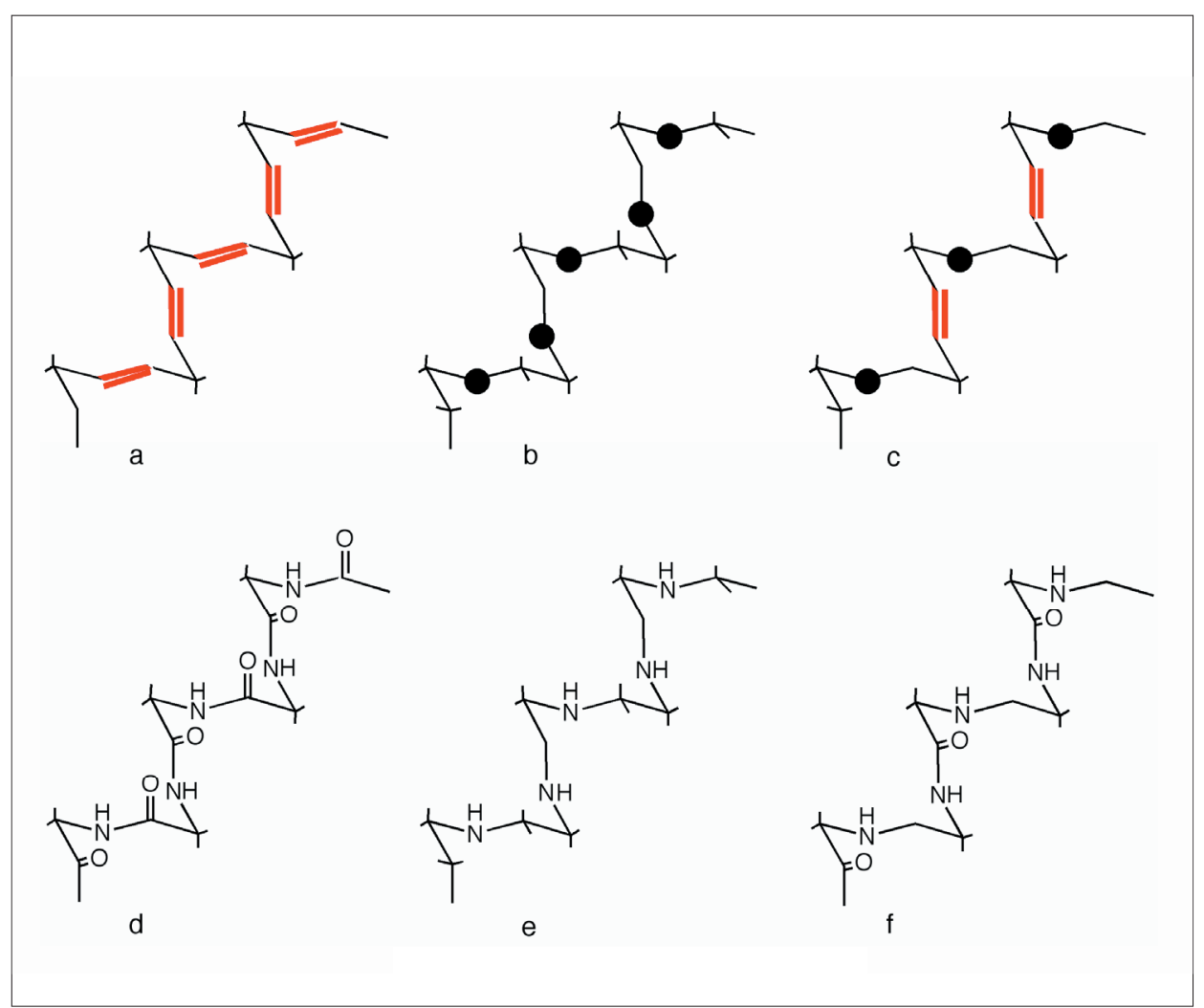

Fig. 23. The idealized conformation of the backbone-core of A-DNA's $(-g /-g)$-conformer equated to the conformation of the backbones of aliphatic oligomer systems containing double bonds (or equivalents thereof) or electronegative centers (black dots) 


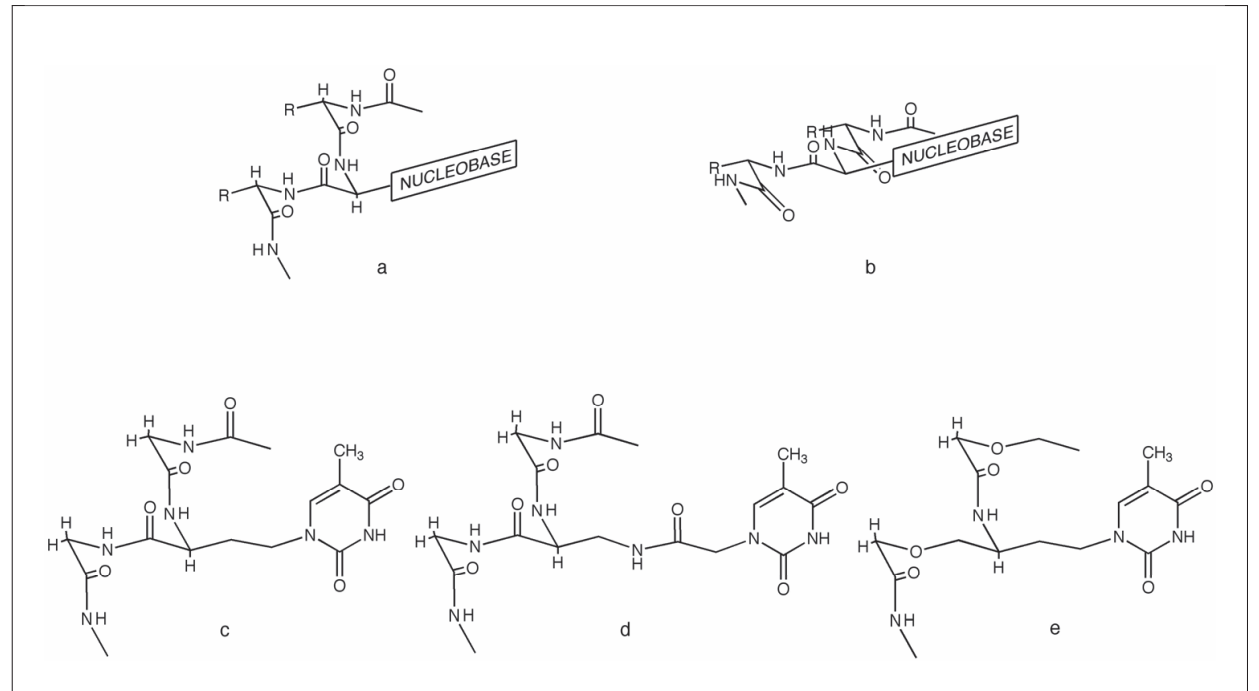

Fig. 24. The two (idealized) backbone conformations of oligo-dipeptide base-pairing systems (a and b), and three experimentally studied systems taken from the literature, depicted in an (idealized) pairing conformation (c, $d$ and $e)$

mations, the specific positioning of the electronegative centers would support the maintenance of the thread's specific folding and have an effect on the backbone's conformational preferences similar to that of the aforementioned double bonds. Taking the NH-group as the electronegative center, the oligomer backbone becomes that of an oligo-ethylenimine, pointing to the possibility that, again depending on the structural details of the attachment of the nucleobase, such a type of structure might serve as the backbone of oligomer systems that cross-pair with DNA and RNA. A similar prediction could be made for a correspondingly nucleobase-tagged oligoethylenoxide backbone.

Finally, there is a third way of maintaining the special conformational relationship of an aliphatic backbone with the $(-g /-g)$ conformation of A-type DNA, namely by any mixed positioning of double bonds (or amide bonds) and electronegative centers along the backbone thread as long the positional requirements stated above remain fulfilled. Fig. 23 depicts with formula c a variant that shows regular alternation between an amide group and an imino group; this variant, interestingly enough, corresponds constitutionally to the (nontagged) backbone of Nielsen's PNA.

Fig. 24 gives the generalized formula of nucleobase-tagged oligo-dipeptide oligomers drawn in the two conformations that correspond to the pairing conformations $(-g /-g$ and $t /-g)$ of homo-DNA and, consequently, A-type DNA and RNA (formulae a and $b$ ). A wide-ranging program of experimental screening of the base-pairing properties of such systems as a function of the structure of the nucleobase-bearing side-chain and, importantly, of the structure type of the nucleobases, is called for.
The residues labeled as $\mathrm{R}$ can be the residue of any alpha-amino acid, preferable one that facilitates water solubility. Only a few representatives of the potentially large diversity of such oligo-dipeptide systems are described in the literature [45]; however, data about self-pairing capabilities of such systems, e.g. of oligomers of type $b$ in Fig. 24, are absent and the reports about their capability to cross-pair with the natural systems conflicting. DNA- and RNAcross-pairing capabilities of such systems seem indeed to depend on the nature of the nucleobase-bearing side-chain, as Masayuki Fujii's well studied and successful oligo-dipeptide system (Fig. 24d) demonstrates [46]. Of special interest in this context is the oligomer of Fig. 24e which corresponds to the type of system pointed to in Fig. 23c and which shows efficient cross-pairing with DNA and RNA [47], in remarkable contrast to the oligomer of Fig. 24c which is reported [47a] not to do so.

In a search for potentially primordial genetic systems within the landscape of nucleobase-tagged oligodipeptides, the main selection criterion for choosing the structure of systems to be studied will have to be a given oligomer system's generational simplicity relative to that of normal natural alpha-oligopeptides and their building blocks, the alpha-amino acids. Thereby, the exploration of the structural diversity of generationally simple heterocycles that could serve as alternative nucleobases, and especially of the kind of 'nucleosidation step' they would allow for, will be challenges to be met [54].

In recent years, a huge amount of empirical information about the structure and base-pairing properties of a large variety of structurally modified analogs of Nielsen's
PNA has become available [44][48][55]. To what extent these data fit into the kind of formal stereochemical exercise discussed here of connecting (idealized) pairing conformations of peptide-type oligomer systems with the 'allowed' (idealized) pairing conformations of homo-DNA, is a question that might deserve a separate analysis.

\section{Acknowledgement}

I would like to express my appreciation and deep gratitude to my postdoctoral students, all marvelous people, some of them extraordinarily so, with whom I had the privilege to collaborate shortly before and after my retirement at ETH. A very special thank goes to Professor Ram Krishnamurthy, member of the first postretirement postdoctoral crew at ETH in 1992 and founding member of my group at Scripps in 1996; it would have been hardly possible to start that group, and definitely impossible to run it since then, without him. At ETH, I enjoy the administrative hospitality and personal friendship of Professor Andrea Vasella; I feel deeply indebted to him.

Received: September 12, 2005

[1] A. Eschenmoser, 'Kon-Tiki-Experimente zur Frage nach dem Ursprung von Biomolekülen', in 'Materie und Prozesse. Vom Elementaren zum Komplexen', Eds. W. Gerok et al., Verh. Ges. Dtsch. Naturforsch. Ärzte, 116. Versammlung, Berlin 1990, p. 135, Wissenschaftl. Verlagsges. mbH, Stuttgart; A. Eschenmoser, 'Warum Pentose- und nicht Hexose-Nucleinsäuren?', Nachr. Chem. Tech. Lab. 1991, 39, 795; A. Eschenmoser, E. Loewenthal, 'Chemistry of Potentially Prebiological Natural Products', Chem. Soc. Rev. 1992, $21,1$.

[2] a) E. Uhlmann, A. Peyman, Chem. Rev. 1990, 90, 543; b) A. De Mesmaeker, R. Haener, P. Martin, H.E. Moser, Acc. Chem. Res. 1995, 28, 366; c) B. Hyrup, P.E. Nielsen, Bioorg. Med. Chem. 1996, 4, 5; d) P. Herdewijn, Liebigs Ann. 1996, 1337; e) C.J. Leumann, Bioorg. Med. Chem. 2002, 10, 841 .

[3] A. Eschenmoser, 'Über organische Naturstoffsynthese: Von der Synthese des Vitamin $B_{12}$ zur Frage nach dem Ursprung der Corrinstruktur', Nova Acta Leopold., Neue Folge 1982, Band 55, Nr. 247, p. 5; A. Eschenmoser, 'Vitamin $\mathrm{B}_{12}$ und präbiotische Naturstoffchemie', Jahresber. 1984, Schweiz. Nationalfonds, Bern, 1985, p.198; G. Ksander, G. Bold, R. Lattmann, C. Lehmann, T. Früh, Y. Xiang, K. Inomata, H.-P. Buser, J. Schreiber, E. Zass, A. Eschenmoser, 'Chemie der $\alpha$ Aminonitrile', 1. Mitt., Helv. Chim. Acta 1987, 70, 1115.

[4] H. Moser, A. Fliri, A. Steiger, G. Costello, J. Schreiber, A. Eschenmoser, Helv. Chim. Acta 1986, 69, 1224; H. Moser, 'Synthese und Eigenschaften von oligo- 
meren Di- und Tri-Peptamidinium-Salzen', ETH-Dissertation Nr. 7925, 1985.

[5] A. Steiger, 'Oligomerisation von Dipeptidnitrilen', ETH-Dissertation Nr. 8367, 1987.

[6] P. Lohse, B. Oberhauser, B. OberhauserHofbauer, G. Baschang, A. Eschenmoser, Croat. Chem. Acta 1996, 69, 535; P. Lohse, 'Synthese und Eigenschaften von oligomeren Nukleodipeptamidinium-Salzen', ETH-Dissertation Nr. 9937, 1992.

[7] M.T. Doel, A.S. Jones, N. Taylor, Tetrahedron Lett. 1969, 10, 2285; H. De Koning, U.K. Pandit, Recl. Trav. Chim. Pays-Bas 1971, 90, 1069; J.D. Buttrey, A.S. Jones, R.T. Walker, Tetrahedron 1975, 31, 73; A.S. Jones, Int. J. Biol. Macromolecules 1979, 1, 194; Yu P. Shvachkin, Zh. Obshch. Khim 1979, 49. 1009; A.B. Cheikh, L.E. Orgel, J. Mol. Evol. 1990, 30, 315.

[8] Unpublished; see however [6]. In retrospect, we realize that the sequence length of an 8-mer (with thymin as nucleobase) is far too short to draw conclusions about an oligomer system's capability of basepairing. Had we in the TNA series (see later) investigated the 8-mer only, we would have failed to observe the system's pairing capacity.

[9] P.E. Nielsen, M. Egholm, R.H. Berg, O. Buchardt, Science 1991, 254, 1497.

[10] A. Eschenmoser, M. Dobler, Helv. Chim. Acta 1992, 75, 218.

[11] R.W. Fischer, 'Allopyranosyl-Nukleinsäure: Synthese, Paarungseigenschaften und Struktur von Adenin-/Uracil-haltigen Oligonukleotiden', ETH-Dissertation Nr. 9971, 1992.

[12] A.G. Helg, 'Allopyranosyl-Nukleinsäure Synthese: Paarungseigenschaften und Struktur von Guanin-/Cytosin-enthaltenden Oligonukleotiden', ETH-Dissertation Nr. 10464, 1994.

[13] U. Diederichsen, 'A. Hypoxanthin-Basenpaarungen in Homo-DNA-Oligonucleotiden. - B. Zur Frage des Paarungsverhaltens von Glucopyranosyl-Oligonucleotiden', ETH-Dissertation Nr. 10122, 1993.

[14] D. Müller, S. Pitsch, A. Kittaka, E. Wagner, C.E. Wintner, A. Eschenmoser, Helv. Chim. Acta 1990, 73, 1410.

[15] J. Hunziker, H.-J. Roth, M. Böhringer, A. Giger, U. Diederichsen, M. Göbel, R. Krishnan, B. Jaun, C. Leumann, A. Eschenmoser, Helv. Chim. Acta 1993, 76, 259.

[16] For a discussion of X-ray structures of phosphodiester groups see Fig. 9 in [10]. Whereas the gauche-gauche conformation appears intrinsically favored, the trans-trans conformation apparently has not been not observed. Stereoelectronic reasoning (generalized anomeric effect) led us originally believe that the gauchetrans conformation should be disallowed; the structure of e.g. pyranosyl-RNA, however, taught us to think differently (see below).
[17] For a complete pictorial presentation of the sequence of stereochemical arguments leading to this result see G. Quinkert, E. Egert, C. Griesinger, 'Aspects of Organic Chemistry', Verlag Helv. Chim. Acta, Basel, 1996, page 144.

[18] G. Otting, M. Billeter, K. Wüthrich, H.J. Roth, C. Leumann, A. Eschenmoser, Helv. Chim. Acta 1993, 76, 2701.

[19] A whole series of attempts in various laboratories to translate the X-ray refraction data of the beautifully crystalline and high-melting homo-DNA-duplex of the self-complementary octamer sequence dd(CGAATTCG) into a consistent X-ray structure turned out to be unexpectedly difficult. According to a private communication of Martin Egli (Vanderbilt University), it is only recently that the structure could be solved by making use of the new methodology of Se-labeling of oligonucleotide strands (unpublished; for the method see [20]).

[20] C.J. Wilds, R. Pattanayek, C. Pan, Z. Wawrzak, M. Egli, J. Am. Chem. Soc. 2002, 124, 14910.

[21] M. Böhringer, H.-J. Roth, J. Hunziker, M. Göbel, R. Krishnan, A. Giger, B. Schweizer, J. Schreiber, C. Leumann, A. Eschenmoser, Helv. Chim. Acta 1992, 75, 1416.

[22] K. Groebke, J. Hunziker, W. Fraser, L. Peng, U. Diederichsen, K. Zimmermann, A. Holzner, C. Leumann, A. Eschenmoser, Helv. Chim. Acta 1998, 81, 375.

[23] M. Tarköy, M. Bolli, B. Schweizer, C. Leumann, Helv. Chim. Acta 1993, 76, 481; C.J. Leumann, Chimia 2001, 55, 295; C.J. Leumann, Bioorg. Med. Chem. 2002, 10, 841 .

[24] P. Herdewijn, Liebigs Ann. 1996, 1337; P. Herdewijn, Biochim. Biophys. Acta 1999, 1489, 167; J. Wengel, Acc. Chem. Res. 1999, 32, 301; S. Obika, D. Nanbu, Y. Hari, J. Andoh, K. Morio, T. Doi, T. Imanishi, Tetrahedron Lett. 1998, 39, 5401; E. Lescrinier, M. Froeyen, P. Herdewijn, Nucl. Acids Res. 2003, 31, 2975.

[25] R. Hammer, postdoctoral report ETH Zürich, 1992; C. Miculka, postdoctoral report ETH Zürich and University of Frankfurt, 1995.

[26] A. Eschenmoser, Science 1999, 284, 2118.

[27] a) S. Pitsch, S. Wendeborn, B. Jaun, A. Eschenmoser, Helv. Chim. Acta 1993, 76, 2161; b) S. Pitsch, S. Wendeborn, R. Krishnamurthy, A. Holzner, M. Minton, M. Bolli, C. Miculka, N. Windhab, R Micura, M. Stanek, B. Jaun, A. Eschenmoser, Helv. Chim. Acta 2003, 86, 4270.

[28] I. Schlönvogt, S. Pitsch, C. Lesueur, A Eschenmoser, B. Jaun, R.M. Wolf, Helv Chim. Acta 1996, 79, 2316.

[29] M. Beier, F. Reck, T. Wagner, R. Krishnamurthy, A. Eschenmoser, Science 1999, 283, 699.

[30] T. Wagner, H.K. Huynh, R. Krishnamurthy, A. Eschenmoser, Helv. Chim. Acta 2002, 85, 399.
[31] F. Reck, H. Wippo, R. Kudick, R. Krishnamurthy, A. Eschenmoser, Helv. Chim. Acta 2001, 84, 1778

[32] O. Jungmann, M. Beier, A. Luther, H.K. Huynh, M.O. Ebert, B. Jaun, R. Krishnamurthy, A. Eschenmoser, Helv. Chim. Acta 2003, 86, 1259.

[33] S. Pitsch, R. Krishnamurthy, M. Bolli, S. Wendeborn, A. Holzner, M. Minton, C. Lesueur, I. Schlönvogt, B. Jaun, A. Eschenmoser, Helv. Chim. Acta 1995, 78 , 1621; M. Bolli, R. Micura, S. Pitsch, A. Eschenmoser, Helv. Chim. Acta 1997, 80, 1901.

[34] M. Bolli, R. Micura, A. Eschenmoser, Chem. Biol. 1997, 4, 309.

[35] H. Wippo, F. Reck, R. Kudick, M. Ramaseshan, G. Ceulemans, M. Bolli, R. Krishnamurthy, A. Eschenmoser, Bioorg. Med. Chem. 2001, 9, 2411.

[36] K.-U. Schöning, P. Scholz, S. Guntha, X. Wu, R. Krishnamurthy, A. Eschenmoser, Science 2000, 290, 1347; K.-U. Schöning, P. Scholz, X. Wu, S. Guntha, G. Delgado, R. Krishnamurthy, A. Eschenmoser, Helv. Chim. Acta 2002, 85, 4111.

[37] B. Jaun, M.O. Ebert (unpublished); see Focus article by N. Hall in Chem. Commun. 2004, 1247.

[38] C.J. Wilds, Z. Wawrzak, R. Krishnamurthy, A. Eschenmoser, M. Egli, J. Am. Chem. Soc. 2002, 124, 13716; P.S. Pallan, C.J. Wilds, Z. Wawrzak, R. Krishnamurthy, A. Eschenmoser, M. Egli, Angew. Chem. Int. Ed. 2003, 42, 5893.

[39] J.C. Chaput, J.K. Ichida, J.W. Szostak, J. Am. Chem. Soc. 2003, 125, 856; J.K. Ichida, K. Zou, A. Horhota, B. Yu, L.W. McLaughlin, J.W. Szostak, J. Am. Chem. Soc. 2005, 127, 2802; see also V. Kempeneers, K. Vastmans, J. Rozenski, P. Herdewijn, Nucleic Acids Res. 2003, 31 , 6221.

[40] G.F. Joyce, L.E. Orgel, 'Prospects for Understanding the Origin of the RNA World', in 'The RNA World', Eds. R.F. Gesteland, T.R. Cech, J.F. Atkins, 2nd. Ed., Cold Spring Harbor Laboratory Press, Cold Spring Harbor, NY, 1999, p. 49.

[41] L. Zhang, A. Peritz, E. Meggers, J. Am. Chem. Soc. 2005, 127, 4174

[42] M.O. Ebert, A. Luther, H.K. Huynh, R. Krishnamurthy, A. Eschenmoser, B. Jaun, Helv. Chim. Acta 2002, 85, 4055.

[43] R. Micura, R. Kudick, S. Pitsch, A. Eschenmoser, Angew. Chem. Int. Ed. Engl. 1999, 38, 680.

[44] P.E. Nielsen, Acc. Chem. Res. 1999, 32, 624; P.E. Nielsen, U. Koppelhus, F. Beck, 'Peptide Nucleic Acid (PNA). A Pseudopeptide with DNA-like Properties', in 'Pseudo-peptides in Drug Discovery', Ed. P.E. Nielsen, Wiley-VCH, Weinheim, 2004, p. 153.

[45] A. Lenzi, G. Reginato, M. Taddei, Tetrahedron Lett. 1995, 36, 1713; A. Lenzi, G. Reginato, M. Taddei, E. Trifilieff, Tetrahedron Lett. 1995, 36, 1717; N.M. 
Howarth, L.P.G. Wakelin, J. Org. Chem. 1997, 62, 5441; P. Garner, J.U. Yoo, Tetrahedron Lett. 1993, 34, 1275; I. Lewis, Tetrahedron Lett. 1993, 34, 5697.

[46] M. Fujii, K. Yoshida, J. Hidaka, T. Ohtsu, Chem. Commun. 1988, 717.

[47] a) M. Kuwahara, M. Arimitsu, M. Sisido, Tetrahedron 1999, 55, 10067; M. Kuwahara, M. Arimitsu, M. Sisido, J. Am. Chem. Soc. 1999, 121, 256; b) K.H. Altmann, C. Schmit Chiesi, C. Garcia-Echeverria, Bioorg. Med. Chem. Lett. 1997, 7 , 1119; C. Garcia-Echeverria, D. Hüsken, C. Schmit Chiesi, K.H. Altmann, Bioorg. Med. Chem. Lett. 1997, 7, 1123.

[48] V.A. Kumar, Europ. J. Org. Chem. 2002, 2021 (review), V.A. Kumar, K.N. Ganesh, Acc. Chem. Res. 2005, 38, 404.

[49] U. Diederichsen, Angew. Chem. 1996, 108, 458; U. Diederichsen, H.W. Schmitt, Tetrahedron Lett. 1996, 37, 475; U. Diederichsen, H.W. Schmitt, Eur. J. Org. Chem. 1998, 827; M.F.H. Hoffmann, A.M. Brückner, T. Hupp, B. Engels, U. Diederichsen, Helv. Chim. Acta 2000, 83, 2580; A.M. Brückner, P. Chakraborty, S.H. Gellmann, U. Diederichsen, Angew. Chem. 2003, 115, 4532.

[50] P. Garner, S. Dey, Y. Huang, J. Am. Chem. Soc. 2000, 122, 2405; see also 'alpha-Helical Peptide Nucleic Acids (alpha-PNAs)' in 'Pseudo-peptides in Drug Discovery', Ed. P.E. Nielsen, Wiley-VCH, Weinheim, 2004, chapter 5, p. 193.

[51] For studies on delta-peptide analogs of pyranosyl-RNA with Gerhard Quinkert at the University of Frankfurt see [52].

[52] G. Karig, A. Fuchs, A. Büsing, T. Brandstetter, S. Scherer, J.W. Bats, A. Eschenmoser, G. Quinkert, Helv. Chim. Acta
2000, 83, 1049; H. Schwalbe, J. Wermuth, C. Richter, S. Szalma, A. Eschenmoser, G. Quinkert, Helv. Chim. Acta 2000, 83, 1079.

[53] A formal transformation of the idealized conformation of a saturated four-center chain containing two vicinal substituents in antiplanar arrangement into the idealized conformation of a 2,3-unsaturated chain with the two substitutents in trans arrangement would in fact require two $60^{\circ}$-rotations around the resulting $\mathrm{sp}^{3} / \mathrm{sp}^{2}$-bonds in order to reach the (idealized) most stable conformations at the allylic positions (allylic hydrogens synplanar with the double-bond axis). Allowing for this implicit conformational change would have to be part of a more detailed analysis of such an adaptation of the pairing conformation of an oligonucleotide to that of an oligopeptide. However, for the sake of pictorial simplicity and clarity, this aspect is not taken into account by Fig. 22-24.

[54] There exists important informational chemistry involving conventional nucleobases and peptidic backbones not based on the oligo-dipeptide (6-bond periodicity) concept: see the work of Ulf Diederichsen on nucleobase-tagged alanyl- and homoalanyl-PNAs [49] and that of Philip Garner on alpha-helical peptide nucleic acids (alpha-PNAs) [50].

[55] Most, if not all of these variants do not belong to the landscape of potentially primordial oligomer systems. However, Nielsen's PNA itself has been considered in this context [44][56].

[56] K.E. Nelson, M. Levy, S. L. Miller, Proc. Natl. Acad. Sci. USA 2000, 97, 3868. 